This is the Author's Accepted Manuscript of the following article: Pérez-Mayán, L., Rodríguez, I., Ramil, M., Kabir, A., Furton, K., \& Cela, R. (2019). Fabric phase sorptive extraction followed by ultra-performance liquid chromatography-tandem mass spectrometry for the determination of fungicides and insecticides in wine. Journal Of Chromatography A, 1584, 13-23. doi: 10.1016/j.chroma.2018.11.025.

(C) 2018 Elsevier B.V. This manuscript version is made available under the CC-BY-NC-ND 4.0 license

\title{
Fabric Phase Sorptive Extraction Followed by Ultra-Performance Liquid Chromatography-Tandem Mass Spectrometry for the Determination of Fungicides and Insecticides in Wine
}

Pérez-Mayán, L. ${ }^{a} ;$ Rodríguez, I. ${ }^{a} ;$ Ramil, M. ${ }^{a \star} ;$ Kabir, A. ${ }^{\text {bै}}$; Furton, K. G. ${ }^{b} ;$ Cela, R. ${ }^{a}$

${ }^{a}$ Department of Analytical Chemistry, Nutrition and Food Sciences, IIAA-Institute for Food Analysis and Research, Universidade de Santiago de Compostela, R/Constantino Candeira SN, 15782 Santiago de Compostela, Spain

b International Forensic Research Institute, Department of Chemistry and Biochemistry, Florida International University, 11200 SW $8^{\text {th }}$ Street, Miami, FL 33199, USA

Edición del artículo publicado en:

Journal of Chromatography A, 1584 (2019) 13-23

https://doi.org/10.1016/j.chroma.2018.11.025 


\section{Abstract}

In this work, fabric phase sorptive extraction (FPSE) is investigated for the extraction and preconcentration of ultra-trace level residues of fungicides (19 compounds) and insecticides (3 species) in wine samples. Subsequently, the preconcentrated analytes are selectively determined using ultra-performance liquid chromatography-tandem mass spectrometry (UPLC-MS/MS). Parameters affecting the efficiency and repeatability of the extraction are evaluated in depth; moreover, the proposed method is characterized in terms of linear response range, trueness, precision and limits of quantification (LOQs). The set-up of the extraction process and the type of coating were the variables exerting the most prominent effects in the repeatability and the yield of the extraction, respectively. Under optimized conditions, samples $(10 \mathrm{~mL}$ of wine diluted with the same volume of ultrapure water) were extracted with a small amount of cellulose fabric (3 discs with $4 \mathrm{~mm}$ of diameter: total surface $0.38 \mathrm{~cm}^{2}$ ) coated with a sol-gel polyethylene glycol sorbent (sorbent amount $3.3 \mathrm{mg}$ ), immersed in the diluted sample, without being in direct contact with the PTFE covered magnetic stir bar. Following the overnight extraction step, analytes were quantitatively recovered using only $0.3 \mathrm{~mL}$ of an $\mathrm{ACN}-\mathrm{MeOH}$ (80:20) mixture. Under equilibrium sampling conditions, the linear response range of the method varied from 0.2 to $200 \mathrm{ng} \mathrm{mL}^{-1}$, with limits of quantification (LOQs) between 0.03 and 0.3 $\mathrm{ng} \mathrm{mL} \mathrm{m}^{-1}$. Relative recoveries ranged from $77 \pm 6 \%$ to $118 \pm 4 \%$, and from $87 \pm 4 \%$ to $121 \pm 6 \%$ for red and white wines, respectively. Application of the optimized method to commercial wines demonstrated the existence of up to 9 out of 22 investigated compounds in the same wine sample. The compound identified at the highest concentration was iprovalicarb (IPR), with a value of $130 \pm 9 \mathrm{ng} \mathrm{mL}^{-1}$ in a commercial white wine.

Keywords: fabric phase sorptive extraction (FPSE), wine analysis, fungicides, ultraperformance liquid chromatography-tandem mass spectrometry (UPLC-MS/MS), sample preparation 
*Corresponding author E-mail: maria.ramil@usc.es

Tel: 0034881814466

${ }^{\text {}}$ Corresponding author

E-mail: akabir@fiu.edu

Tel: +1 3053482396 


\section{Introduction}

Production of vinification grapes is the agriculture activity involving the highest application rate of organic fungicides, defined as mass of active ingredient per hectare [1]. At the same time, the use of insecticides has also been increased to control pests, which either directly damage vines or serve as vectors for virus affecting vine plants [2]. A fraction of the pesticides remaining in the harvested grapes is not removed during must fermentation; thus, they persist in the elaborated wines. Presence of these residues in wine poses potential health risks to consumers and therefore it must be closely monitored. However, in the European Union (EU), the maximum residue levels (MRLs) of pesticides in wine are far to be regulated. Instead, the recommendation of the International Organization of Vine and Wine, OIV (10\% of MRLs for vinification grapes) is generally accepted [3]. Therefore, the monitoring of fungicides and insecticides in commercial wines becomes an overwhelming analytical challenge and a valuable tool to understand the frequency and intensity of human exposure, to develop future regulations, and to verify the quality standards of ecologic labelled wines.

Although some studies describe wine analysis by direct injection of the filtered sample in the chromatographic system [4,5], a sample preparation step is usually required to remove unwanted components, to increase the concentration of pesticides and/or to make the wine matrix compatible with the chromatographic instrument (in case of gas chromatography (GC) based methods). Solid-phase extraction (SPE) [6-10] and QuEChERS [11-14] are the most common sample preparation methodologies to extract and/or to concentrate multiclass pesticides from wine. Despite the widespread use of the above techniques in food control laboratories, there is an increasing concern about the voluminous consumption of organic solvents during sample preparation, a trend to move towards the so-called Green Analytical Chemistry (GAC) supported extraction methodologies; and also a continuous search to reduce resources dedicated to sample 
preparation. In this sense, microextraction techniques have undergone a great deal of transformations over the last years.

The pioneer and the most popular of these formats is the solid-phase microextraction (SPME) technique [15]. Its combination with GC methods can be considered totally solvent free and it has been applied in different occasions for the determination of pesticides in wine $[16,17]$. On the other hand, for non-GC amenable compounds, the success of SPME followed by LC analysis is limited $[18,19]$. Other drawbacks of SPME are the cost of the commercial sorbents (polymer coated fibers) that need to be reused, their limited variety, and the small volume of sorbent incorporated in SPME fibers that results in poor detection/quantification sensitivity, particularly when combined with solvent desorption. Stir-bar sorptive extraction (SBSE) presents the advantage of a larger amount of sorbent; nevertheless, the number of available coatings is even more limited compared to SPME [20]. In order to overcome this drawback, SBSE has recently incorporated a solvent-assisted approach to enhance the recovery of polar pesticides from wine [21].

Regarding liquid-phase microextraction (LPME) approaches, dispersive liquid-liquid extraction (DLLME) has been used for pesticides determination in wine, either as extraction-concentration technique [22], or in combination with other techniques such as SPE [6]. DLLME shows very fast mass transfer kinetics and high extraction yields in comparison with other microextraction techniques, such as SPME. However, in DLLME separation of phases is a critical issue, in particular when applied to complex matrices as in the case of wines. Also, most extractants are not directly compatible with reversedphase LC separation.

Fabric phase sorptive extraction (FPSE), developed by Kabir and Furton [23], is a recent microextraction technique with several appealing features. The first one is the coating approach, which is not based on physical adhesion of a thin layer of the polymer on the substrate surface but on sol-gel coating technology [24]. Conventional surface 
coating technology creates a thick/thin layer of an organic polymer on the surface of the fiber substrate which is subsequently immobilized by a free radical cross-linking reaction. The physical adhesion of the polymer coating created in this manner displays many weaknesses including poor thermal and solvent stability and limits the application substantially. On the other hand, sol-gel coating technology used in FPSE chemically binds the organic polymer with the substrate surface. Due to the strong covalent bonding between the substrate and the sol-gel derived sorbent coating, coated fabrics can be exposed to any organic solvent for analytes elution after the extraction and to a $\mathrm{pH}$ range from 1 to 12, without any loss of microextraction performance.

A second advantageous feature of FPSE is the physical format of the microextraction device [25], which incorporates a substantially larger sorbent amount than SPME fibers. FPSE uses chemically stable permeable fabrics (i.e. cotton, polyester or fiberglass) as the substrate to host different polymeric sorbents via sol-gel process. FPSE simultaneously utilizes an inorganic precursor, a fabric substrate and an organic polymer that collectively determine the overall polarity and selectivity of the FPSE media. As such, unlike conventional microextraction techniques including SPME or SBSE, the polarity and selectivity of the FPSE media can be easily customized based on the polarity and other physico-chemical characteristics of the target analyte(s).

Over the last years, FPSE has been successfully employed in a number of unique applications including the concentration of estrogens [26], cytostatic drug residues [27], non-steroidal anti-inflammatory drugs [28], triazine herbicides [29] and UV-stabilizers [30] in water; to the extraction of amphenicols [31] and sulfonamides [32] from raw milk, and to the determination of additives in food packaging materials [33], among others.

The aim of this work is to assess the suitability of the FPSE technique for the extraction of a relevant number of pesticides (mainly fungicides), belonging to different chemical classes, from wine samples. Extracted compounds are selectively determined by ultra-performance liquid chromatography (UPLC) with tandem mass spectrometry 
(MS/MS) detection. The effects of the extraction set up, the sorbent coating, the ionic strength of the sample and the extraction time in the responses of selected analytes are carefully investigated. Solid-phase extraction (SPE) was used as an auxiliary technique in order to determine the absolute extraction efficiency of FPSE.

\section{Experimental}

\subsection{Material and chemicals}

All substrates, chemicals, reagents, and solvents used in the current project were of highest quality. Substrate cotton fabric ( $100 \%$ cellulose) was purchased from Jo-Ann Fabric (Miami, FL, USA). Organic polymers: poly(tetrahydrofuran), poly(ethylene glycol), poly(caprolactone triol), poly(ethylene glycol)-block-poly(propylene glycol)-blockpoly(ethylene glycol); solvents: acetone and dichloromethane; sol-gel precursor methyltrimethoxysilane (MTMS), and sol-gel catalyst trifluoroacetic acid were purchased from Sigma-Aldrich (St. Louis, MO, USA). Organic polymer poly(caprolactone)-blockpoly(dimethylsiloxane)-block-poly(caprolactone) was purchased from Gelest (Morrisville, PA, USA). Sodium hydroxide and hydrochloric acid were obtained from Fisher Scientific (Milwaukee, WI, USA). Sol solutions were centrifuged in an Eppendorf Microcentrifuge Model 5415R (Eppendorf North America Inc., Hauppauge, NY, USA) prior to sol-gel coating. A Fisher Scientific Digital Vortex Mixture (Fisher Scientific, Pittsburg, PA, USA) was used to ensure thorough mixing of different solutions. Sol solution was sonicated in a 2510 BRANSON Ultrasonic Cleaner (Branson Ultrasonics, Danbury, USA) to obtain bubble-free sol solution. A Barnstead Nanopure Diamond (Model D11911) deionized water unit (Dubuque, IA, USA) provided ultra-pure deionized water $\left(18.2 \mathrm{M} \Omega \mathrm{cm}^{-1}\right)$ for sol-gel synthesis and substrate treatment in the USA lab.

Methanol and acetonitrile (HPLC grade) were purchased from Merck (Darmstadt, Germany). Formic acid was obtained from Sigma-Aldrich. Sodium chloride was purchased from VWR Prolabo (Llinars del Vallés, Spain). 
Standards of fungicides (19 compounds) and insecticides ( 3 species) were provided by Sigma-Aldrich (St. Louis, MO, USA) and Dr. Ehrenstorfer (Augsburg, Germany). The selection of pesticides, together with their abbreviated names and $\log D$ values (calculated at the typical pH of wine samples: 3.5 units) are compiled in Table 1. Stock solutions (ca. $1000 \mu \mathrm{g} \mathrm{mL}^{-1}$ ) of each compound were prepared in methanol and stored at $-20 \stackrel{\circ}{ }{ }^{\circ}$. Mixed solutions (ca. $10 \mu \mathrm{g} \mathrm{mL}^{-1}$ ) were made in the same solvent and kept at 4 ㅇ $\mathrm{C}$ for a maximum of 4 weeks.

SPE cartridges (OASIS HLB $200 \mathrm{mg}$ ) were obtained from Waters Corporation (Milford, MS, USA).

\subsection{Preparation of sol-gel sorbent coated FPSE media}

The broad-spectrum polarity of the target compounds (log Kow values ranging from 1.65 for Metalaxyl, MET, to 4.96 for Chlorpyrifos, $\mathrm{CHL}$ ) in an extremely complex sample matrix like wine, as well as their ultra-trace level concentrations, present a great analytical challenge that is difficult to circumvent. It is hard to speculate the appropriate sorbent material that would efficiently isolate and preconcentrate the target analytes in presence of concomitant entities. As such, five different coated fabrics, widely varied in their overall polarity, were synthesized and investigated: sol-gel Carbowax 20M (sol-gel CW20M), sol-gel polycaprolactone-block-poly- dimethylsiloxane-block-polycaprolactone (sol-gel PCAP-PDMS-PCAP), sol-gel Caprolactone triol (sol-gel CAP triol), sol-gel poly(tetrahydrofuran) (sol-gel PTHF), and sol-gel poly(ethylene glycol)-blockpoly(propylene glycol)-block-poly(ethylene glycol) (sol-gel PEG-PPG-PEG). All sol-gel coatings were created on cotton fabric ( $100 \%$ cellulose). In addition to the organic polymer, sol solutions were prepared using methyl trimethoxysilane (MTMS) as the inorganic precursor, trifluoroacetic acid (TFA) as the acid catalyst, methylene chloride: acetone $(50: 50 \mathrm{v} / \mathrm{v})$ as the solvent system, and water as the hydrolytic agent. Relative molar ratio between the organic polymer: inorganic precursor: acetone: methylene 
chloride: catalyst: water was maintained at $1: 7.1 \times 10^{-3}: 1.94: 2.3: 0.75: 3$, for sol-gel CW20M; 1: 0.13: 1.94: 2.3: 0.75: 3, for sol-gel PEG-PPG-PEG; 1: 0.57: 1.94: 2.3: 0.75: 3, for sol-gel PTHF; 1: 0.025: 1.94: 2.3: 0.75: 3, for sol-gel PCAP-DMS-PCAP; and 1: 0.50: 1.94: 2.3: $0.75: 3$, for sol-gel CW20M. The pretreatment of the cellulose fabric substrate prior to the sol-gel coating, the sol-gel immersion coating process to create chemically bonded sorbent coatings on the substrate surface, and the conditioning and cleaning of the sol-gel sorbent coated FPSE media have been described extensively elsewhere $[26,34]$. Sol solution composition, sorbent loading, the schematics of sol-gel sorbent coated FPSE media, and other relevant information for the coated fabrics used in this study are given as supplementary information, Table S1.

Sol-gel sorbent coated FPSE media were prepared as large sheets $(40 \mathrm{~cm} \times 10 \mathrm{~cm}$, $\left.400 \mathrm{~cm}^{2}\right)$, which were subsequently cut into smaller pieces with different shapes $(1 \mathrm{~cm}$ x $1 \mathrm{~cm}$ square pieces, using scissors; and $4 \mathrm{~mm}$ diameter discs, employing a puncher). Before being used in the extraction experiments, the sol-gel sorbent-coated FPSE square/ circular disc units were rinsed with methanol and ultrapure water and allowed to dry at room temperature. Given the small size of FPSE units used in the current study, unless otherwise stated, they were considered as single use devices.

\subsection{Samples and sample preparation}

Red (Cabernet Sauvignon, Tempranillo and Mencía varieties) and white (Chardonnay, Verdejo and Albariño grape) wines were acquired from local supermarkets in Santiago de Compostela, Spain. Wine bottles were kept at room temperature, in a dark room, before opening. Thereafter, they were maintained at $4 \stackrel{\circ}{ } \mathrm{C}$ for a maximum of 5 days. The information related to the analyzed samples (alcohol content and grape variety) was obtained from labels on the wine bottles.

Fabric phase sorptive extraction experiments were performed in $22 \mathrm{~mL}$ volume glass vessels containing $10 \mathrm{~mL}$ of wine, the same volume of ultrapure water, a PTFE covered 
magnetic stir bar and the FPSE media. Vials were closed using a PTFE layered septum, crimped with an aluminum cap. Extractions were carried out at room temperature, with samples placed in a multi-position magnetic stirrer. During extraction, vessels were stirred at a relatively low speed (200 rpm) to prevent the formation of air bubbles at the interface between the aqueous sample and the coated fabric sorbent. After a given extraction time, FPSE units were removed from the wine solution with tweezers, rinsed with ultrapure water and dried with a lint-free tissue. The coated fabrics were transferred to $2 \mathrm{~mL}$ glass vessels and compounds were desorbed with a mixture of organic solvents compatible with their further separation by reversed-phase LC. Before injection into the UPLC-MS/MS system, the obtained extract was passed through a $0.22 \mu \mathrm{m}$ syringe filter. Unless otherwise stated, sample preparation conditions were optimized with a red wine sample (Carbernet Sauvignon variety) spiked at $50 \mathrm{ng} \mathrm{mL}^{-1}$.

Under final working conditions, analytes were concentrated using sol-gel CW20M coated FPSE media. The FPSE media was used in a $4 \mathrm{~mm}$ diameter disc format. Three discs were attached to the septum of the vessel with a vertically hanging stainless-steel pin. This experimental set-up prevents the magnetic stir bar striking the coated FPSE media, which might lead to sorbent losses and, thus, to a poor extraction repeatability. Extractions were carried out overnight. Thereafter, the stainless steel pin, with the inserted FPSE media units, was removed and rinsed with ultrapure water. Subsequently, the extracted analytes were desorbed by soaking the FPSE discs with $0.3 \mathrm{~mL}$ of a $\mathrm{ACN}: \mathrm{MeOH}(80: 20)$ solution for $15 \mathrm{~min}$.

\subsection{LC-ESI-MS/MS parameters}

Compounds were determined using a LC-MS/MS XEVO TQD, triple quadrupole mass spectrometer, acquired from Waters (Milford, MA, USA) and furnished with a Z spray $\mathrm{ESI}$ source, operated in the positive ionization mode (ESI+). A rapid resolution column Agilent (Wilmington, DE, USA) UPLC Zorbax Eclipse Plus $\mathrm{C}_{18}(50 \mathrm{~mm} \times 2.1 \mathrm{~mm}$, 
$1.8 \mu \mathrm{m}$ ) was used for the pesticides separation together with a $C_{18} 2.1 \mathrm{~mm} \mathrm{i.} \mathrm{d.} \mathrm{guard}$ cartridge from Phenomenex (Torrance, CA, USA). Both were maintained at $40{ }^{\circ} \mathrm{C}$. The injection volume was $1.5 \mu \mathrm{L}$. The mobile phase consisted of acetonitrile (B) and ultrapure water $(\mathrm{A})$, both containing $0.1 \%$ of formic acid at a constant flow of $0.4 \mathrm{~mL} \mathrm{~min}^{-1}$. The gradient was as follows: $2 \% \mathrm{~B}(0 \mathrm{~min}), 50 \% \mathrm{~B}(1.3-2.8 \mathrm{~min}), 100 \% \mathrm{~B}(6.4-7.5 \mathrm{~min})$, and $2 \%$ B (7.6 - $10 \mathrm{~min})$.

Retention times, precursor and product ions for each compound together with cone voltages and collision energies for each transition are given in Table 1 . The relative deviations of retention times through a typical sequence, involving more than 50 injections, remained below $0.15 \%$ for all the compounds. Additional instrumental parameters, including ESI variables were adopted from a previous study [10].

2.5. Characterization of FPSE efficiency and quantification of pesticides in wine samples SPE was used as a reference technique to evaluate the absolute extraction efficiency (EE) of the optimized FPSE method under equilibrium sampling conditions. To this end, $4 \mathrm{~mL}$ of the diluted wine solution, previously exposed to the FPSE sorbent, were concentrated by SPE under reported elsewhere [10]. Aliquots $(4 \mathrm{~mL})$ of the same spiked solution, not submitted to FPSE, were also concentrated by SPE. The EE (\%) of the FPSE process was calculated as the difference in responses measured in the SPE extracts corresponding to spiked wine aliquots, before and after FPSE extraction, divided by the first one and multiplied by 100 .

Enrichment factors (EFs) were calculated as the ratio between wine and extract volumes (10 and $0.3 \mathrm{~mL}$, respectively) multiplied by the EE achieved for each compound. Log K (distribution constant of pesticides between the sol-gel CW20M sorbent and the sample matrix) were calculated using the following equation: $K=(E E \times B) /(1-E E)$. This expression is obtained after a mass balance in a 2-phases system. Where $\mathrm{K}$ is the distribution constant, $\mathrm{B}$ is the ratio sample mass/ coating mass and EE is the extraction 
yield, and considering a sample mass of $20000 \mathrm{mg}$, a coating mass of $8.63 \mathrm{mg} \mathrm{cm}^{-2}$ and a disc surface of $0.13 \mathrm{~cm}^{2}$.

The effect of the wine matrix in the efficiency of the sample preparation process was evaluated by comparing responses obtained for red (Cabernet Sauvignon) and white (Verdejo) wine samples, spiked at increased concentration levels, in the range from 0.5 to $200 \mathrm{ng} \mathrm{mL}^{-1}$. The ratio between the slopes of the calibration curves obtained for each compound in both matrices was multiplied by 100 . The larger the difference of the obtained value to 100 the higher the variation in the performance of the reported methodology between red and white wines.

Accuracy of the proposed method was investigated using red and white wine samples, elaborated with grapes from different varieties, spiked at two different concentration levels. The differences between responses for spiked and non-spiked fraction of each sample were compared against matrix-matched calibration curves obtained for spiked aliquots of two wines without detectable concentrations of target compounds.

\section{Results and discussion}

\subsection{Selection of FPSE substrate and sorbent chemistry}

Due to the wide dispersion of log Kow values (from 1.65 to 4.96) of the pesticides involved in the current study and aqueous nature of wine sample matrix, hydrophilic cotton fabric ( $100 \%$ cellulose) was the rational choice among many available substrate candidates. This substrate was coated with five organic polymers possessing different polarities: Carbowax 20M (highly polar containing poly(ethylene glycol), $\mathrm{H}\left[\mathrm{OCH}_{2} \mathrm{CH}_{2}\right]_{n} \mathrm{OH}$ as the building block); poly(ethylene glycol)-block-poly(propylene glycol)-block-poly(ethylene glycol) copolymer (moderately polar, containing poly(ethylene glycol), $\quad \mathrm{H}\left[\mathrm{OCH}_{2} \mathrm{CH}_{2}\right]_{n} \mathrm{OH}$ and poly(propylene glycol), $\left(\mathrm{H}\left[\mathrm{OCH}\left(\mathrm{CH}_{3}\right) \mathrm{CH}_{2}\right]_{n} \mathrm{OH}\right)$ as the building blocks); poly(caprolactone)-blockpoly(dimethylsiloxane)-block-poly(caprolactone) copolymer (medium polar, containing 
poly(caprolactone), $\quad\left(\mathrm{C}_{6} \mathrm{H}_{10} \mathrm{O}_{2}\right)_{n}$ and poly(dimethylsiloxane), $\left(\mathrm{CH}_{3}\right)_{3} \mathrm{SiO}\left[\left(\mathrm{CH}_{3}\right) \mathrm{HSiO}\right]_{n} \mathrm{Si}\left(\mathrm{CH}_{3)_{3}}\right.$ building blocks), poly(caprolactone triol) (highly polar, containing $\mathrm{C}_{2} \mathrm{H}_{5} \mathrm{C}\left[\mathrm{CH}_{2} \mathrm{O}\left[\mathrm{CO}\left(\mathrm{CH}_{2}\right) 5 \mathrm{O}\right]_{n} \mathrm{H}_{3}\right.$ building block; and poly(tetrahydrofuran) (medium polar containing $\mathrm{H}\left(\mathrm{OCH}_{2} \mathrm{CH}_{2} \mathrm{CH}_{2} \mathrm{CH}_{2}\right)_{n} \mathrm{OH}$ building block, see Table $\mathrm{S} 1$.

MTMS (possessing 3 sol-gel active sites) was selected as the sol-gel precursor. Thus, the methyl pendant group in the silica backbone of the coated fabrics (Table S1) can also exert London dispersion interaction towards the target analytes.

Due to the difference in organic polymer chain length and their use in the sol solution, the sorbent loading per unit area of the FPSE media varied widely during the sol-gel coating process. Sorbent loading values ranged from $3.46 \mathrm{mg} \mathrm{cm}^{-2}$, for the sol-gel polycaprolactone coating, to $8.63 \mathrm{mg} \mathrm{cm}^{-2}$, for the sol-gel CW20M coating (Table S1).

\subsection{Set-up of FPSE experiments}

Preliminary extraction experiments were performed with $1 \times 1 \mathrm{~cm}$ fabrics, freely floating and moving in the diluted wine solution [28, 30], whilst stirring using a PTFE coated magnetic stir bar (10 $\times 3 \mathrm{~mm})$. Extractions were carried out overnight, using the sol-gel CW20M sorbent coated FPSE membranes. Subsequently, FPSE sorbent pieces were desorbed with $1 \mathrm{~mL}$ of $\mathrm{ACN}$ : $\mathrm{MeOH}(80: 20)$ solution. This mix of solvents has been recommended for the quantitative extraction of fungicides and insecticides from reversed-phase SPE cartridges [10], whilst many of the red wine pigments remained attached to the SPE sorbent.

Under these conditions, a poor repeatability in the responses of target pesticides was obtained. Since the desorption step was verified to be comprehensive, variability was related to the sampling process. For most compounds, the relative standard deviations (RSDs) in their peak areas remained above 20\%. During extraction, it was often observed that the fabric sorbent folded or rolled up around the magnetic stir bar, which modified the surface of contact with the sample. Moreover, coating loss was suspected since the transparency of the stirred solution decreased with time. 
In a further series of experiments, sol-gel CW20M sorbent coated FPSE membranes were cut into $4 \mathrm{~mm}$ diameter discs, which were subsequently suspended at middle height of the extraction vessel, with a stainless steel pin attached to the septum. In this configuration, the magnetic stir bar did not interact with the coated fabrics, avoiding mechanical abrasion problems. The use of smaller size fabrics also prevented changes in the surface of contact with the sample due to folding or rolling problems. Different series of assays were carried out using red wine aliquots spiked at the same concentration level. In the first one, just one fabric was used per vessel. The second group of extractions was performed introducing four discs, with the same coating, in each vessel. In both cases, after overnight extraction, FPSE membrane units were rinsed with ultrapure water, dried with a lint-free tissue and each disc was individually desorbed using $1 \mathrm{~mL}$ of $\mathrm{ACN}$ : $\mathrm{MeOH}(80: 20)$. For most compounds, the obtained RSD values stayed in the range between 10 to $20 \%$, with little differences between the two series of experiments, Fig. 1. Likely, this data indicate that: 1) the size of the circular FPSE membrane was too small to guarantee a homogeneous amount of coating per disc, and 2) competitive sorption of compounds to the walls of the extraction vessel does not explain the poor variability of the extraction experiments. In the latter situation, RSDs would have decreased when different discs were introduced in the same vessel, followed by their individual desorption.

In a $3^{\text {rd }}$ series of experiments, a relatively large unit of sol-gel sorbent coated FPSE membrane (ca. $100 \mathrm{~cm}^{2}$ surface) was divided into $4 \mathrm{~mm}$ diameter discs. These units were mixed, conditioned and then 3 discs were dipped into the same sampling solution. Thereafter, they were desorbed together using $1 \mathrm{~mL}$ of $\mathrm{ACN}$ : $\mathrm{MeOH}(80: 20)$ solution. Under these conditions, a noticeable improvement in the repeatability of the extraction desorption process was attained with RSD values from 2 to $12 \%$, Fig. 1. Thus, further FPSE experiments were carried out using three FPSE membrane discs (4 mm diameter) suspended inside the diluted wine samples. Re-optimization of desorption solvent 
volume proved that just $0.3 \mathrm{~mL}$ of the extraction solvent mixture recovered around 90 $95 \%$ of compounds trapped in the extraction discs. Since discs were regarded as single use devices, in further extractions, the desorption solvent volume was reduced to 0.3 $\mathrm{mL}$, which provided higher concentration factors. A scheme of the sample preparation set up is provided as Fig. 2.

\subsection{Selection of optimum sol-gel sorbent coated FPSE media}

Fig. 3 compares the responses obtained with the above materials for duplicate extractions. Data are normalized to those obtained with the sol-gel CW20M coating. The sol-gel CW20M coating followed by the sol-gel PEG-PPG-PEG coating provided the highest normalized responses for most compounds. The lowest relative efficiencies were provided by the sol-gel CAP-triol coating, and the medium polarity ones, sol-gel PCAPPDMS-PCAP and sol-gel PTHF coatings were found not to be very efficient in extracting the target analytes with the exception of compounds TRIF, CHLM and CHL, which are relatively non-polar species (Table 1). Based on these results, the sol-gel CW20M coated fabrics were selected to continue with the optimization of the method.

The contribution of the cotton substrate $(100 \%$ cellulose polymer) to the extraction process was also evaluated in comparison to that obtained using sol-gel CW20M coated FPSE membranes. For most of the compounds, the relative extraction efficiencies of the cotton substrate stayed below $4 \%$ of those attained using the sol-gel CW20M coated FPSE membranes (Fig. S2).

The scanning electron micrograph (SEM) image of the sol-gel CW20M coated media demonstrating the homogeneous distribution of the sol-gel CW20M coating around the cellulose micro fibrils is reported elsewhere [35]. FT-IR spectra of a) uncoated cellulose fabric, b) CW20M polymer and c) sol-gel CW20M coated PSE medium are provided in Fig. S1. Substantial reduction of the $\mathrm{O}-\mathrm{H}$ stretching band $\left(3332 \mathrm{~cm}^{-1}\right)$. in sol-gel CW20M 
coated FPSE media compared to uncoated cellulose fabric suggests successful chemical integration of the sol-gel CW20M network to the cellulose substrate, via condensation between the reactive $\mathrm{OH}$ functional groups of cellulose fabric, the $\mathrm{OH}$ functional groups of hydrolyzed MTMS precursor and the terminal $\mathrm{OH}$ functional groups of the CW20M polymer [36].

\subsection{Assessing of ionic strength impact}

The effect of the ionic strength in the efficiency of the FPSE process was evaluated by introducing $1 \mathrm{~g}$ of $\mathrm{NaCl}$ in the extraction vessel. Fig. S3 shows the obtained-responses as normalized values to those observed without salt, $n=3$ replicates. For most species, $\mathrm{NaCl}$ did not play a significant role in their extraction efficiencies. In case of triadimenol (TRI), a relatively polar compound ( $\log \mathrm{D} 3.27$, Table 1 ), an enhanced response (ca. $20 \%$ ) was observed when adding $1 \mathrm{~g}$ of $\mathrm{NaCl}$ to the diluted sample. Likely, the salting out effect decreased the solubility of this fungicide in the diluted wine matrix, increasing its affinity for the sol-gel CW20M coated FPSE disc. Pyrimethanil (PYR) and cyprodinil (CYP) were better extracted without salt. Both are basic species with pKa values (3.44 and 3.10, respectively) close to the $\mathrm{pH}$ of the diluted wine sample (3.5 units); at this $\mathrm{pH}$ the compounds are stable, but they are partially protonated, what limits their extraction efficiency. Moreover, the increase in the ionic strength of the aqueous solution increases the solubility of the protonated forms of both compounds (salting in effect), reducing their affinity towards the sorbent. In view of data depicted in Fig. S3, no salt was added to the diluted samples in further extractions.

\subsection{Extraction equilibrium time and efficiency}

The influence of the extraction time on the recoveries of the FPSE process was investigated in the interval from 1 to $25 \mathrm{~h}$. The time-course profiles obtained for 4 selected fungicides (azoxystrobin, AZO; tebuconazole,TEB; fenhexamid FEN and MET) 
belonging to different chemical classes (strobilurin, azolic, hydroxyphenyl amide and phenylamide), are provided in Fig. 4. The rest of the compounds showed similar extraction profiles. The improvement in the extraction efficiency is evident at short extraction times; thereafter, between 6 and $15 \mathrm{~h}$, responses still increased slightly, to stay constant at longer retention times (from 15 to $25 \mathrm{~h}$ ). The unusually long extraction equilibrium time for the target analytes may be attributed to the presence of analytes concomitants present in the wine matrix that include ethanol, glycerol, organic acids, tannins and phenolics. We assume that the slow diffusion rate is directly related to the complexity of the wine matrix. Due to the high concentrations of these interfering chemicals compared to the concentrations of the analytes, the probability of the latter species to reach the interaction sites of the sol-gel sorbent coating for a successful analyte-sorbent interaction is very low at any given time. On the other hand, the long extraction equilibrium time unequivocally attests the high analyte retention capacity of the sol-gel sorbent, which is far to be saturated even after being exposed to wine sample for more than $25 \mathrm{~h}$.

Kinetics of solid-phase microextraction equilibrium techniques might be controlled by two different factors: (1) the rate of mass transfer at the interface between the liquid sample and the sorbent, and/or (2) the diffusion rate of the compounds from the sample to the interface with the sorbent. As shown in the supplementary section (Fig. S4), kinetics of the current FPSE process is not increased when doubling the number of coated discs (and thus the surface of the interface with the sample); therefore, the $2^{\text {nd }}$ of the above cited factors is what limits the kinetics of the microextraction process.

Equilibrium times reported in this study are compared to those reported in previous applications of the FPSE technique. As example, Racamonde et al. [28] achieved equilibrium times around $2 \mathrm{~h}$ for the extraction of pharmaceuticals from water samples. During application of FPSE to the extraction of triazine herbicides from water samples, equilibrium was not achieved within $2 \mathrm{~h}$ [29]. FPSE of carbamazepine from water 
required equilibrium times longer than $8 \mathrm{~h}$ [37]. In summary, equilibrium times in FPSE widely vary depending on the analytes and the sample matrix.

Under equilibrium conditions, the FPSE extraction efficiency (EE) was investigated using SPE to determine the concentration of each compound remaining in the FPSE vessel. The obtained values, considering two different amounts of sol-gel CW20M coated FPSE membranes, are shown in Table 2. EEs ranged from a minimum of $10 \%$ for TRI $(\log D 3.27)$ to a maximum of $78 \%$ for the relatively non-polar fungicide trifloxystrobin (TRIF) and the insecticide CHL (log D 4.77 and 4.78, respectively) for 3 discs. When using 6 fabric discs, the EEs of compounds with lower affinity to the sol-gel CW20M coating (PYR, CYP, MET and TRI) were doubled. On the other hand, little improvement was observed for the rest of species. Considering that desorption of the 6 discs required increasing the volume of solvent from 0.3 to $1 \mathrm{~mL}$ (data not shown), the use of 3 coated fabric units was maintained as the best compromise among EEs, EFs and solvent and sorbent requirements. Considering 3 fabric discs, EFs ranged from 3 (TRI) to 26 (TRIF and $\mathrm{CHL})$.

Calculated log $\mathrm{K}$ values for the extraction process are also shown in the last column of Table 2. From these values the efficiency of the extraction (EE) can be predicted for different sample and coated sorbent amounts.

The plots of EEs versus log D values are provided as supplementary information, Fig. S5. Somehow, the larger the log D value of a given compound, the higher its EEs. However, two of the most polar compounds, PYR and MET, display EE values (24\% and $35 \%$, respectively) higher than that obtained for TRI (log D 3.27, EE 10\%). As a result, the correlation between both factors was limited, Fig. S5. In any case, it must be taken into account that the $\log D$ data are calculated values, obtained using the ChemspiderChemaxon software. In addition, log D values, corresponding to an octanol: water system, might not be applicable to estimate the distribution of the compounds between the sol-gel CW20M coating: diluted wine system considered in this research. 
In order to explain the discrepancy between $\log D$ values and the extraction efficiency values of the target analytes, the number of hydrogen bond donors and acceptors of each analyte was evaluated and tabulated (Supplementary Table S2). As a general trend, the higher the combined number of hydrogen bond donor and acceptor in an analyte, the higher was the extraction efficiency. However, two analytes may have the same combined number of hydrogen bond donor and acceptor although they are far apart from each other in their log $D$ values. As such, both polarity of each compound as well as the combined number of hydrogen bond donor and acceptor may play role in its analyte-sorbent interactions, and consequently, its extraction by the sol-gel sorbent.

\subsection{Method performance}

Once extraction conditions were optimized, the linearity of the proposed methodology was evaluated. Wine aliquots, spiked at nine different concentration levels from 0.2 to $200 \mathrm{ng} \mathrm{mL}^{-1}$, were extracted in duplicate. Two different wine samples with negligible residues of pesticides, elaborated from Carbenet Sauvignon (13.5\% ethanol) and Verdejo (12.5\% ethanol) grape varieties (red and white wine, respectively), were employed in the study.

In first place, the performance of the method was assessed under equilibrium conditions (overnight sampling). For both wine matrices, a good linearity was obtained within the above interval of concentrations (Table 3) without using any internal standard correction. The normalized ratios between the slopes of addition curves in both matrices varied from 70 to $135 \%$. The observed slope differences can be due to several sources: (1) possible variations in the FPSE efficiency as function of the sample matrix and/or (2) changes in the efficiency of ESI ionization depending on the wine characteristics. Whatever may have been the responsible for such differences, the adopted decision was the use of two different calibration curves: one for red wine and the other one for white wine quantification. The achieved LOQs, calculated for the red wine matrix using $0.3 \mathrm{~mL}$ of desorption solvent, were estimated from the lowest calibration level which rendered a 
signal to noise above 10 for the Q1 transition, at the same time that the Q2/Q1 ratio remained in the range of values given in Table $1( \pm 30 \%$ as established in the SANTE guide [38]). LOQs varied from $0.03 \mathrm{ng} \mathrm{mL}^{-1}$ for compounds such as PEN, FLU, BEN and TRIF to $0.33 \mathrm{ng} \mathrm{mL}^{-1}$ for CHLM. In the most critical case (FLU, the pesticide with the lowest $M R L$ value for vinification grapes), the obtained $L O Q\left(0.03 \mathrm{ng} \mathrm{mL}^{-1}\right)$ is more than two orders of magnitude lower than the EU MRL $\left(10 \mathrm{ng} \mathrm{g}^{-1}\right)$, Table 3. For the rest of compounds, LOQs remain three orders of magnitude below MRLs for grapes. When compared with values achieved in previous studies, the LOQs compiled in Table 3 are significant lower than those reported for SPE techniques (from 0.1 to $15 \mathrm{ng} \mathrm{mL}^{-1}$, depending on the compound) $[9,10]$ and also than those reported for QuEChERS (ca. $\left.10 \mathrm{ng} \mathrm{mL}^{-1}\right)[11,12]$. It is worth noting that LOQs, obtained in a previous combination of SPE and UPLC-MS/MS [10], correspond to the use of same determination conditions as in the current study.

Given the excellent LOQs provided by the method, we have also evaluated the linearity, the wine matrix effects in the slopes of addition curves, and the LOQs under nonequilibrium extraction conditions, considering a sampling time of $3 \mathrm{~h}$. Obtained values are shown as supplementary information, Table S3. Determination coefficients $\left(R^{2}\right)$ are also close to unit. Slope ratios varied in the same range of values as those shown in Table 3, and LOQs still remained below the $1 \mathrm{ng} \mathrm{mL}^{-1}$ level for most compounds.

Accuracy of the analytical methodology was evaluated at two different addition levels: $50 \mathrm{ng} \mathrm{mL}^{-1}$ and $10 \mathrm{ng} \mathrm{mL}^{-1}$, for different samples of red and white wines. Spiked and nonspiked aliquots of each sample were processed in triplicate, under equilibrium extraction conditions. Differences between peak areas for each compound were compared with those obtained for the calibration curves obtained for spiked aliquots of the Carbenet Sauvignon and the Verdejo wines, for red and white wines, respectively. Obtained values are summarized in Table 4. For the upper spiked level, relative recoveries ranged from $76 \%$ (FEN) to $121 \%$ (TEB), with standard deviations (SD) remaining below $9 \%$. For the 
lower spiked level, recoveries varied within similar values; however, standard deviations increased up to $20 \%$. Globally, data in Table 4 can be considered as acceptable taking into account the complexity of the wine sample matrix, and the fact that no internal surrogate was employed to compensate for possible changes in the efficiency of concentration and desorption steps.

Finally, despite of being considered as single use extraction devices, the stability of the sol-gel CW20M coated fabrics through the extraction - desorption process was evaluated by extracting five wine aliquots (spiked at the same concentrations ) with the same coated fabrics. Responses were normalized to those found in the first extraction. The obtained data (Fig. S6) did not show losses of the extraction efficiencies with the number of cycles.

\subsection{Analysis of real samples}

The developed and validated method was finally applied to determine the concentrations of pesticide residues in nine commercial wine samples, five white wines and four red ones. Obtained data are compiled in Table 5. Figure 5 shows the LC-ESI-MS/MS chromatograms obtained for compounds quantified in sample code 1. Positive identifications are based on retention time match with values obtained for spiked samples (maximum difference $0.1 \mathrm{~min}$, Table 1) and differences of the Q2/Q1 ratios lower than $30 \%$, Table 1 . The number of pesticides, above method LOQs, in the processed samples varied from 2 to 9 . In general, their concentrations stayed at low levels (below $10 \mathrm{ng} \mathrm{mL}^{-}$ $\left.{ }^{1}\right)$. Nevertheless, ametoctradin (AME), FEN and boscalid (BOS) were found at concentrations between 10 and $20 \mathrm{ng} \mathrm{mL}^{-1}$ in several samples. TEB even reached $28 \mathrm{ng}$ $\mathrm{mL}^{-1}$. Finally, the highest observed concentration in the processed wines corresponded to IPR. This compound reached a value of $130 \mathrm{ng} \mathrm{mL}^{-1}$ in one of the white wines (Table 5). Although relatively high, this concentration still remains below $10 \%$ of the EU MRL for vinification grapes (2000 $\mathrm{ng} \mathrm{g}^{-1}$, Table 2). 
Despite the measured values did not violate the OIV maximum recommended values, it is worth noting that most of the detected compounds possess topological polar surface area (TPSA) values below $90 \AA \AA$, Table S2. Thus, they may penetrate the cell membranes and even pass through the blood-brain barrier [39], in case they survive through the digestion process.

\section{CONCLUSIONS}

For the first time, FPSE followed by UPLC-ESI-MS/MS has been successfully optimized and validated for the determination of a broad group of fungicides and three insecticides in wine samples. The set-up of the FPSE process and the type of coating were the variables exerting the most important effects in the repeatability and the yield of the extraction. The proposed methodology provides accurate concentration values in samples spiked at different concentration levels and a reduced consumption of organic solvents in comparison to other techniques, such as SPE and QuEChERS. When FPSE extractions are carried out under equilibrium conditions, unmatched LOQs are obtained. Compounds diffusion from the wine matrix to the FPSE sorbent was a slow, although continuous process of several hours. Long equilibrium times can be balanced with the simultaneous, unattended concentration of several samples in one, or several, multiposition stirring plates. Another option, when maximum sensitivity is not the main requirement of the analysis, is shortening the duration of the sampling step. A $3 \mathrm{~h}$ extraction period guaranteed LOQs still below $1 \mathrm{ng} \mathrm{mL}^{-1}$ for the set of target analytes. Application of the developed method to commercial wine samples confirmed the presence of fungicide residues in this matrix, with the maximum measured level observed for iprovalicarb (IPR).

\section{Acknowledgements}


This study has been supported by the Spanish Government, Xunta de Galicia and E.U. FEDER funds (projects CTQ2015-68660-P and GRC-ED431C). L.P-M acknowledges a FPU contract to the Spanish Ministry of Education. 


\section{References}

[1]http://www.endure-network.eu/endure_publications/deliverables, deliverable DR1.23, accessed on $15^{\text {th }}$ may 2018.

[2] T.J. Jones, M. Nita, Spatio-temporal association of GLRaV-3-infected grapevines, and effect of insecticidal treatments on mealybug populations in Virginia vineyards, Eur. J. Pant. Pathol. 145 (2016) 885-900

[3] OIV, Résidus de Pesticides, Limites Autoriseés: Classement par Pays et par Pesticide, Office International de la Vigne et du Vin, Paris, 1995.

[4] J.D. Berset, S. Mermer, A. E. Robel, V. M. Walton, M. L. Chien, J. A. Field, Direct residue analysis of systemic insecticides and some of their relevant metabolites in wines by liquid chromatography- mass spectrometry, J. Chromatogr. A 1506 (2017) 45-54.

[5] Z. He, Y. Xu, L. Wang, Y. Peng, M. Luo, H. Cheng, X. Liu, Wide-scope screening and quantification of 50 pesticides in wine by liquid chromatography/quadrupole time-of-flight mass spectrometry combined with liquid chromatography/quadrupole linear ion trap mass spectrometry, Food Chem. 196 (2016) 1248-1255.

[6] T. Rodríguez-Cabo, I. Rodriguez, M. Ramil, A. Silva, R. Cela, Multiclass semi-volatile compounds determination in wine by gas chromatography accurate time-of-flight mass spectrometry, J. Chromatogr. A 1442 (2016) 107-17.

[7] M. Pelajic, G. Pecek, D. Mutavdzic Pavlovic, C. D. Vitali, Novel multiresidue method for determination of pesticides in red wine using gas chromatography- mass spectrometry and solid phase extraction, Food Chem. 200 (2016) 98-106.

[8] A. Economou, H. Botitsi, S. Antoniou, D. Tsipi, Determination of multi-class pesticides in wines by solid-phase extraction and liquid chromatography-tandem mass spectrometry, J. Chromatogr. A 1216 (2009) 5856-67.

[9] P. Pérez-Ortega, B. Gilbert-López, J. F. García-Reyes, N. Ramos-Martos, A. MolinaDíaz, Generic sample treatment method for simultaneous determination of multiclass pesticides and mycotoxins in wines by liquid chromatography-mass spectrometry, J. Chromatogr. A 1249 (2012) 32-40.

[10] G. Castro, L. Pérez-Mayán, T. Rodríguez-Cabo, I. Rodríguez, M. Ramil, R. Cela, Multianalyte, high-throughput liquid chromatography tandem mass spectrometry method for the sensitive determination of fungicides and insecticides in wine, Anal. Bioanal. Chem. 410 (2018) 1139-1150.

[11] G. Martínez, A. Morales, A. Maestro, S. Cermeno, J. Oliva, A. Barba, Determination of nine fungicides in grape and wine using QuEChERS extraction and LC/MS/MS analysis, J. AOAC Int. 98 (2015) 1745-51. 
[12] P. Paya, M. Anastassiades, D. Mack, I. Sigalova, B. Tasdelen, J. Oliva, et al. Analysis of pesticide residues using the Quick Easy Cheap Effective Rugged and Safe (QuEChERS) pesticide multiresidue method in combination with gas and liquid chromatography and tandem mass spectrometric detection, Anal. Bioanal. Chem. 389 (2007) 1697-714.

[13] X. Wang, M. J. Telepchak, Determination of pesticides in red wine by QuEChERS extraction, rapid mini-cartridge cleanup and LC-MS-MS detection, LC-GC Europe 26 (2013) 66-76.

[14] J. Wang, W. Cheung, UHPLC/ESI-MS/MS determination of 187 pesticides in wine. J. AOAC Int. 99 (2016) 539-557.

[15] C. L. Arthur, J. Pawliszyn, Solid phase microextraction with thermal desorption using fused silica optical fibers, Anal. Chem. 62 (1990) 2145-2148.

[16] J. Martins, C. Esteves, T. Simoes, M. Correia, C. Delerue-Matos. Determination of 24 pesticides residues in fortified wines by Solid-Phase Microextraction and Gas Chromatography-Tandem Mass Spectrometry, J. Agric. Food. Chem 59 (2011) 68476855.

[17] C. G. Zambonin, M. Quinto, N. De Vietro, F. Palmisano, Solid-phase microextraction - gas chromatography mass spectrometry: A fast and simple screening method for the assessment of organophosphorus pesticides residues in wine and fruit juices, Food Chem. 86 (2004) 269-274.

[18] S. Millan, M. C. Sampedro, N. Unceta, M. A. Goicolea, E. Rodríguez, R. J. Barrio, Coupling solid-phase microextraction and high-performance liquid chromatography for direct and sensitive determination of halogenated fungicides in wine, J. Chromatogr. A 995 (2003) 135-142.

[19] J. Wu, C. Tragas, H. Lord, J. Pawliszyn, Analysis of polar pesticides in water and wine samples by automated in-tube solid-phase microextraction coupled with highperformance liquid chromatography-mass spectrometry, J. Chromatogr. A 976 (2002) 357-367.

[20] Y. Hayasaka, K. MacNamara, G. A Baldock, R. L. Taylor, A. P. Pollnitz. Application of stir bar soptive extraction for wine analysis, Anal. Bioanal. Chem. 375 (2003) 948-55. [21] N. Ochiai, K. Sasamoto, F. David, P. Sandra, Solvent-assisted stir bar sorptive extraction by using swollen polydimethylsiloxane for enhanced recovery of polar solutes in aqueous samples: Application to aroma compounds in beer and pesticides in wine. J. Chromatogr. A 1455 (2016) 45-56. 
[22] B. Chen, F. Wu, W. Wu, B. Jin, L. Xie, W. Feng, G. Ouyang, Determination of 27 pesticides in wine by dispersive liquid-liquid microextraction and gas chromatographymass spectrometry. Microchem. J. 126 (2016) 415-422.

[23] A. Kabir, K. G. Furton, Fabric phase sorptive extractors, US Patent No. 9,283,544, Unites States Patent and Trademark Office, 2016. https://www.uspto.gov/patentsapplication-process/search-patents. Accessed on October $5^{\text {th }}, 2018$.

[24] S. L. Chong, D. Wang, J. D. Hayes, B. W. Wilhite, A. Malik, Sol-gel coating technology for the preparation of solid-phase microextraction fibers of enhanced thermal stability, Anal. Chem. 69 (1997) 3889-3898.

[25] I. Bruheim, X. Liu, J. Pawliszyn, Thin-film microextraction, Anal. Chem. 75 (2003) 1002-1010.

[26] R. Kumar, G. Heena, A. K. Malik, A. Kabir, K. G. Furton, Efficient analysis of selected estrogens using fabric phase sorptive extraction and high performance liquid chromatography-fluorescence detection, J. Chromatogr. A 1359 (2014) 16-25.

[27] S. Santana-Viera, R. Guedes-Alonso, Z. Sosa-Ferrera, J. J. Santana-Rodríguez, A. Kabir, K. G. Furton, Optimization and application of fabric phase sorptive extraction coupled to ultra-high performance liquid chromatography tandem mass spectrometry for the determination of cytostatic drug residues in environmental waters, J. Chromatogr. A 1529 (2017) 39-49.

[28] I. Racamonde, R. Rodil, J. B. Quintana, B. J. Sieira, A. Kabir, K. G. Furton, R. Cela, Fabric phase sorptive extraction: A new sorptive microextraction technique for the determination of non-steroidal anti-inflammatory drugs from environmental water samples, Anal. Chim. Acta 865 (2015) 22-30.

[29] M. Roldan-Pijuan, R. Lucena, S. Cardenas, M. Valcarcel, K. G. Furton, Stir fabric phase sorptive extraction for the determination of triazine herbicides in environmental waters by liquid chromatography, J. Chromatogr. A 1376 (2015) 35-45.

[30] S. Montesdeoca-Esponda, Z. Sosa-Ferrera, A. Kabir, K. G. Furton, J. J. SantanaRodríguez, Fabric phase sorptive extraction followed by UHPLC-MS/MS for the analysis of benzotriazole UV stabilizers in sewage samples, Anal. Bioanal. Chem. 407 (2015) 8137-8150.

[31] V. Samanidou, L. D. Galanopoulos, A. Kabir, K. G. Furton, Fast extraction of amphenicols residues from raw milk using novel fabric phase sorptive extraction followed by high-performance liquid-chromatography - diode array detection, Anal. Chim. Acta 855 (2015) 41-50.

[32] E. Karageorgou, N. Manousi, V. Samanidou, K. G. Furton, Fabric phase sorptive extraction for the fast isolation of sulfonamides residues from raw milk followed by high 
performance liquid chromatography with ultraviolet detection, Food Chem. 196 (2016) 428-436.

[33] M. Aznar, P. Alfaro, C. Nerin, A. Kabir, K. G. Furton, Fabric phase sorptive extraction: An innovative sample preparation approach applied to the analysis of specific migration from food packaging, Anal. Chim. Acta. 936 (2016) 97-107.

[34] A. Kabir, K. G. Furton, A. Malik, Innovations in sol-gel microextraction phases for solvent-free sample preparation in analytical chemistry, Trends Anal. Chem. 45 (2013) 197-28.

[35] M. Aznar, S. Úbeda, C. Nerín, A. Kabir, K. G. Furton, Fabric phase sorptive extraction as a reliable tool for rapid screening and detection of freshness markers in oranges, J. Chromatogr. A 1500 (2017) 32-42.

[36] A. Kabir, R. Mesa, J. Jurmain, K. G. Furton, Fabric phase sorptive extraction explained, Separations 4 (2017) 21.

[37] S.S. Lakade, F. Borrull, K.G. Furton, A. Kabir, N. Fontanals, R.M. Marcé, Comparative study of different fabric phase sorptive extraction sorbents to determine emerging contaminants from environmental water using liquid chromatography-tandem mass spectrometry, Talanta 144 (2015) 1342-1351.

[38] Guidance document on analytical quality control and method validation procedures for pesticide residues and analysis in food and feed. SANTE/11813/2017.EuropeanCommission.https://ec.europa.eu/food/sites/food/files/pla nt/docs/pesticides mrl guidelines wrkdoc 2017-11813.pdf. Accessed on July 26th, 2018

[39] P. Ertl, B. Rohde, P. Selzer, Fast calculation of molecular polar surface area as a sum of fragment-based contributions and its application to the prediction of drug transport properties. J. Med. Chem. 43 (2000) 3714-3717. 


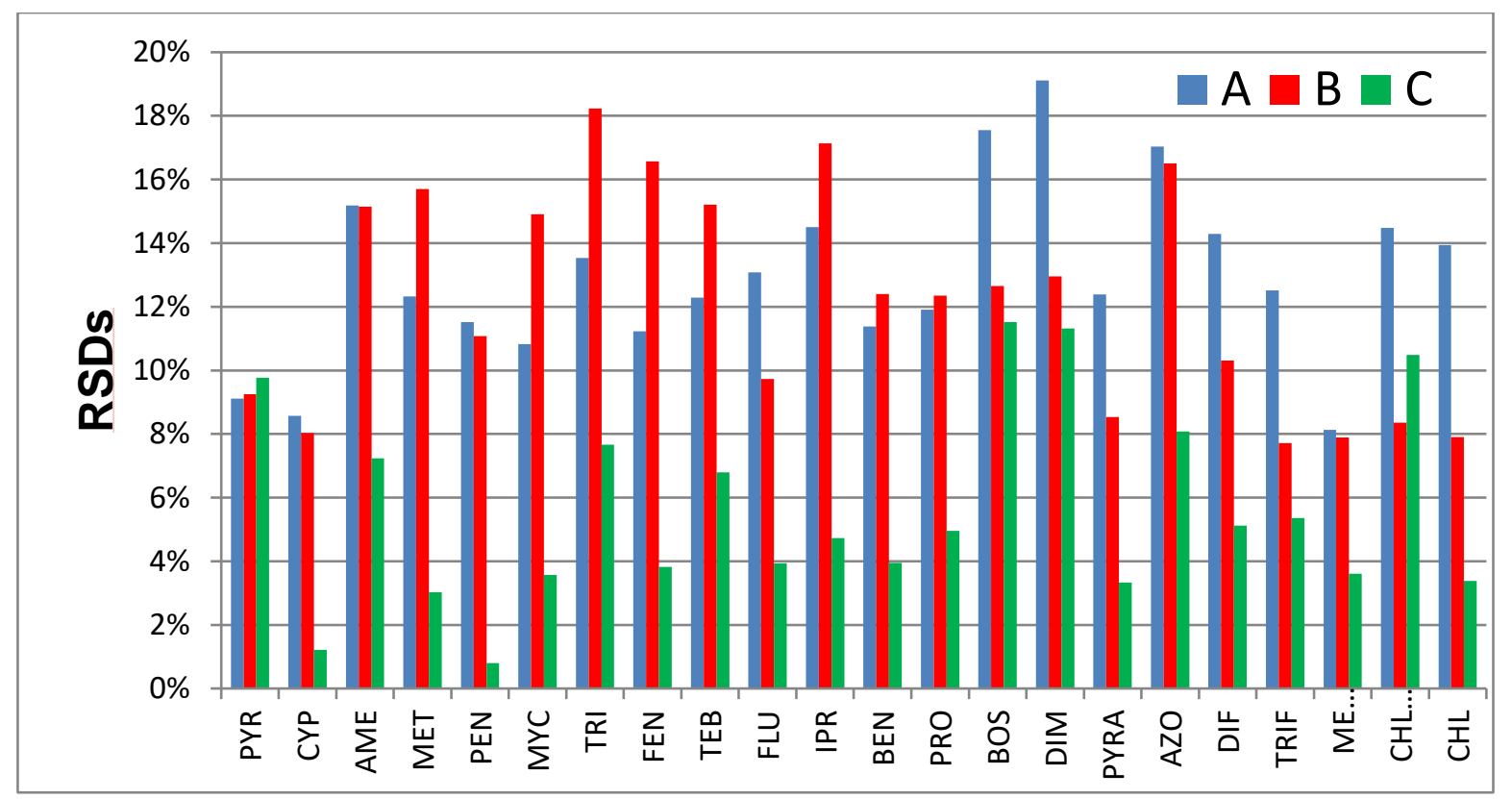

Fig. 1. Relative standard deviations (RSDs) obtained in the extraction of spiked red wine aliquots (addition level $50 \mathrm{ng} \mathrm{mL}^{-1}$ ) using sol-gel CW20M coated $4 \mathrm{~mm}$ diameter FPSE discs. A, single disc per sample, $n=5$ replicates. $B$, four discs per sample followed by their individual desorption, $\mathrm{n}=4$ samples (12 extracts). $\mathrm{C}$, three discs per sample, desorbed in the same vial, $\mathrm{n}=5$ samples. 
1. EXTRACTION

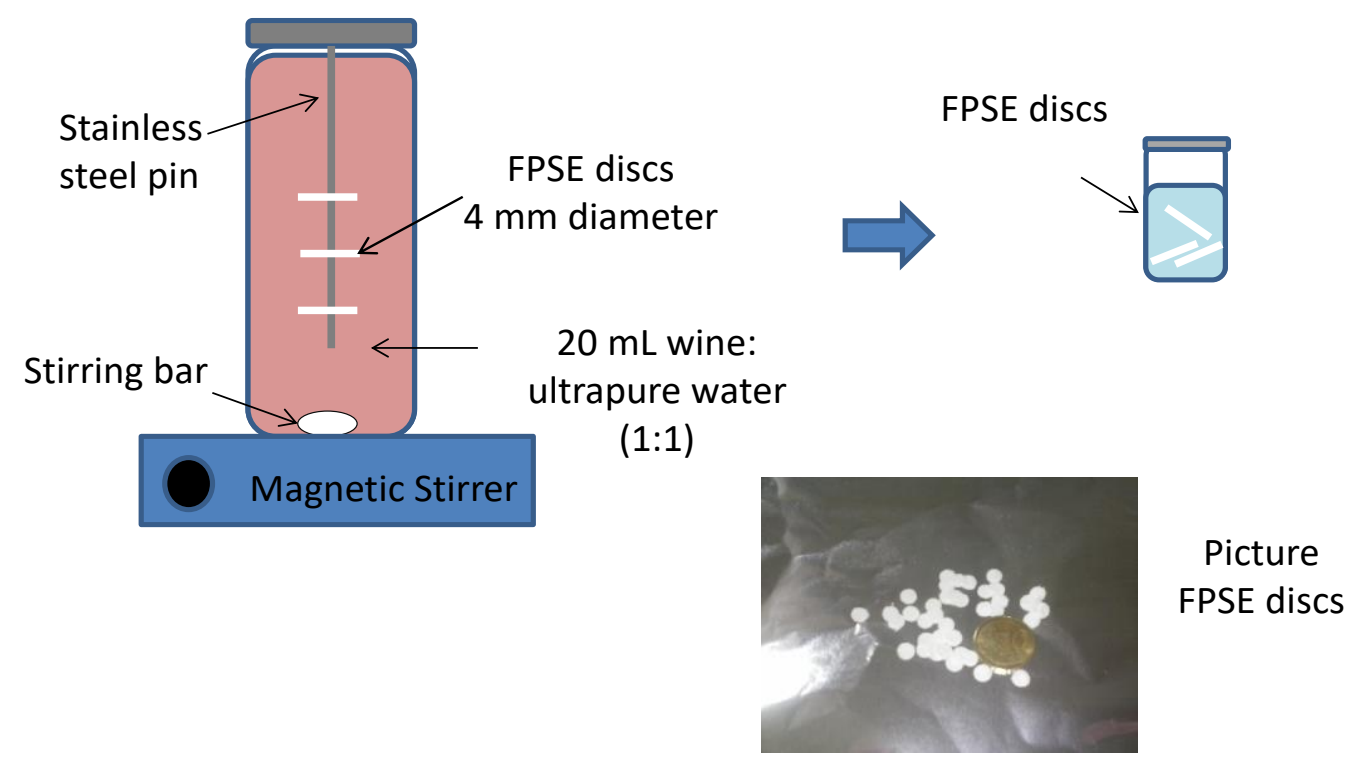

Fig. 2. Scheme of the experimental set-up used in the FPSE process and picture of circled shaped coated fabrics. 




Fig. 3. Normalized responses obtained as function of the polymeric coating in the FPSE discs. Average values for duplicate extractions normalized to sol-gel CW20M. 
AZO
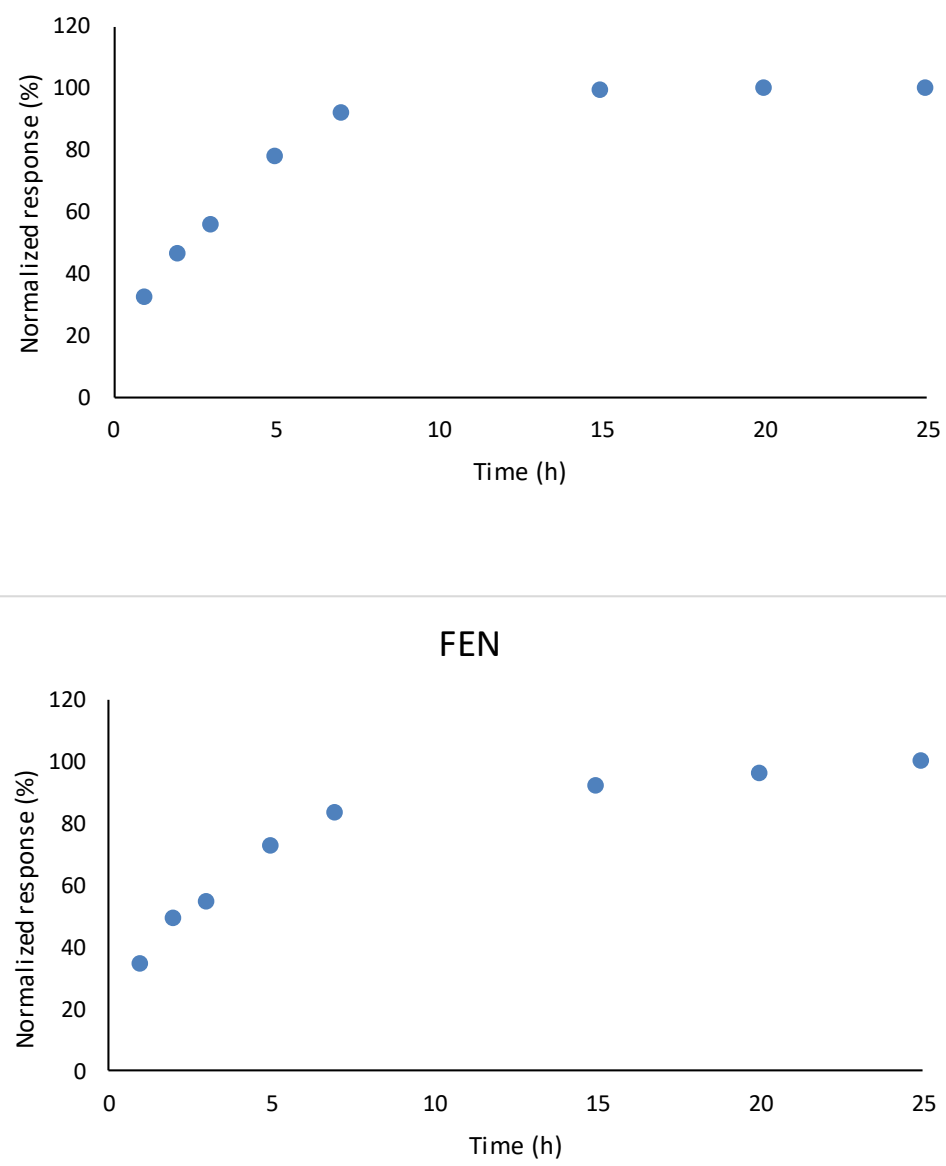

FEB

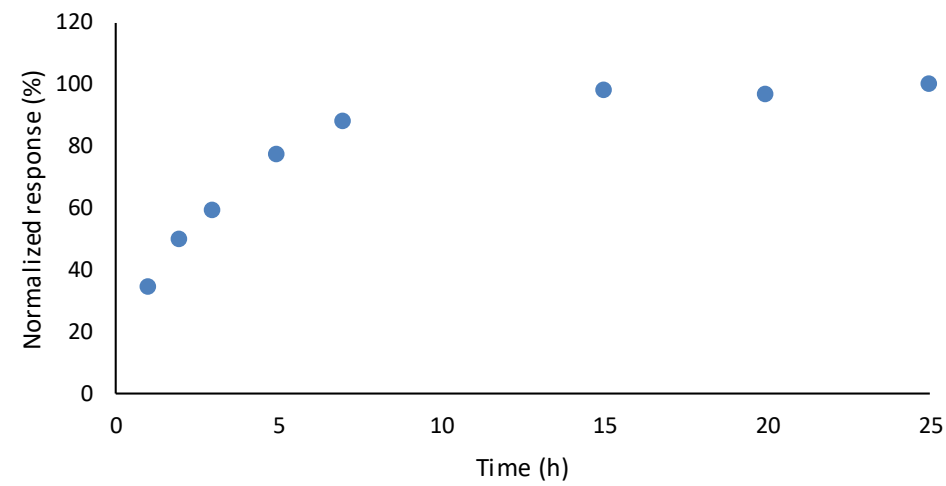

MET

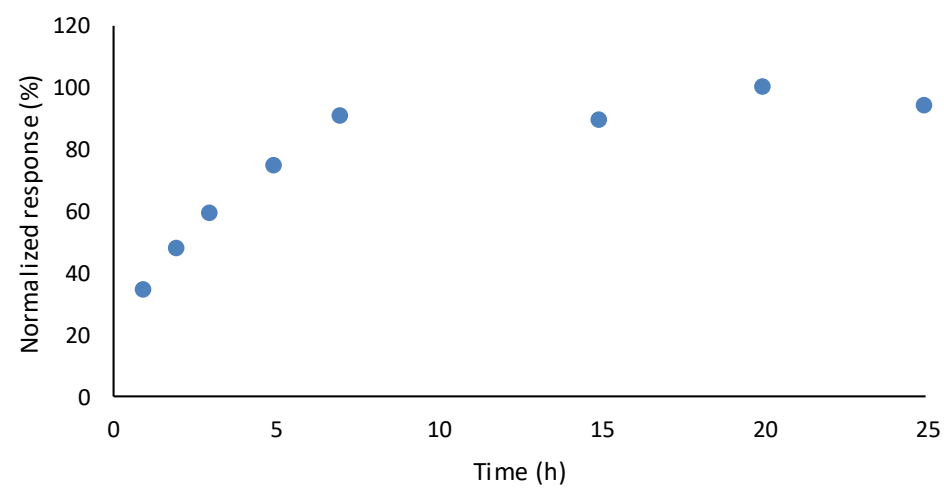

Fig. 4. Time-course of the FPSE process for selected compounds. Each point represents the average response for duplicate extractions.

31 



Fig. 5. LC-ESI-MS/MS chromatograms for compounds quantified in wine sample code 1 (Table 5). Upper and lower chromatographic traces correspond to Q1 and Q2 transitions. Retention time data and Q2/Q1 ratios are included in the figure. 
Table 1. List of target compounds with abbreviated names, $\log \mathrm{D}$ values (calculated data at $\mathrm{pH} 3.5$ ) and MS/MS determination parameters

\begin{tabular}{|c|c|c|c|c|c|c|c|c|}
\hline Compound & Abbreviation & $\log D$ & $\begin{array}{l}\text { Retention } \\
\text { time (min) }\end{array}$ & $\begin{array}{c}\text { Precursor } \\
\text { ion }\left([\mathrm{M}+\mathrm{H}]^{+},\right. \\
\text {Da })\end{array}$ & $\begin{array}{c}\text { Cone } \\
\text { voltaje (v) }\end{array}$ & Q1 (CE, v) & $\begin{array}{l}\text { Q2 (CE, } \\
\text { v) }\end{array}$ & $\begin{array}{l}\text { Q2/Q1 } \\
\text { ratio }\end{array}$ \\
\hline aPyrimethanil & PYR & 2.16 & 2.7 & 200.0 & 51 & $107.0(24)$ & $82.0(24)$ & 0.71 \\
\hline${ }^{a}$ Cyprodinil & CYP & 3.07 & 3.1 & 226.0 & 56 & $93.0(33)$ & $108.0(25)$ & 0.61 \\
\hline${ }^{a} A m e t o c t r a d i n$ & AME & 3.93 & 3.3 & 276.0 & 60 & $176.0(35)$ & $70.0(50)$ & 0.16 \\
\hline aMetalaxyl & MET & 2.12 & 2.8 & 280.1 & 26 & $220.1(13)$ & $192.1(17)$ & 0.57 \\
\hline aPenconazole & PEN & 4.18 & 4.2 & 284.0 & 34 & $70.1(16)$ & $159.0(34)$ & 0.31 \\
\hline aMyclobutanil & MYC & 3.63 & 3.7 & 289.1 & 34 & $70.2(18)$ & $125.1(32)$ & 0.29 \\
\hline aTriadimenol & TRI & 3.27 & 3.2 & 296.1 & 21 & $70.2(10)$ & $99.1(15)$ & 0.13 \\
\hline aFenhexamid & FEN & 4.79 & 3.9 & 302.1 & 41 & $97.2(22)$ & $55.3(38)$ & 0.44 \\
\hline aTebuconazole & TEB & 3.68 & 4.0 & 308.0 & 40 & $70.1(22)$ & $125.0(40)$ & 0.07 \\
\hline aFlusilazol & FLU & 4.66 & 4.0 & 316.0 & 36 & $247.0(18)$ & $165.0(28)$ & 0.78 \\
\hline alprovalicarb & IPR & 3.59 & 3.6 & 321.1 & 28 & $119.1(16)$ & $203.1(10)$ & 0.42 \\
\hline aBenalaxyl & BEN & 4.13 & 4.9 & 326.1 & 26 & $148.0(20)$ & $91.0(34)$ & 0.67 \\
\hline aPropiconazole & PRO & 4.32 & 4.5 & 342.0 & 46 & $69.0(22)$ & $159.0(34)$ & 0.59 \\
\hline aBoscalid & BOS & 4.92 & 3.9 & 342.9 & 41 & $139.9(20)$ & $307.0(20)$ & 0.11 \\
\hline${ }^{\text {aDDimethomorph }}$ & DIM & 3.28 & $3.1 ; 3.2$ & 388.1 & 40 & $300.9(20)$ & $165.0(30)$ & 0.65 \\
\hline aPyraclostrobin & PYRA & 4.69 & 5.2 & 388.1 & 31 & $193.9(12)$ & $163.0(25)$ & 0.66 \\
\hline${ }^{\mathrm{a} A z o x y s t r o b i n}$ & AZO & 4.22 & 3.8 & 404.0 & 28 & $372.0(15)$ & $329.0(30)$ & 0.19 \\
\hline${ }^{\text {aD }}$ ifenoconazole & DIF & 4.85 & 4.9 & 406.0 & 46 & $251.1(25)$ & $111.1(60)$ & 0.34 \\
\hline aTrifloxystrobin & TRIF & 4.77 & 5.6 & 409.0 & 34 & $186.0(16)$ & $145.0(40)$ & 0.44 \\
\hline${ }^{\mathrm{b}}$ Methiocarb & METH & 3.13 & 3.4 & 226.0 & 28 & $169.0(10)$ & $121.0(22)$ & 0.58 \\
\hline${ }^{\mathrm{b}}$ Chlorpyrifos methyl & CHLM & 4.07 & 5.4 & 321.8 & 34 & $125.0(20)$ & $289.9(16)$ & 0.26 \\
\hline${ }^{\mathrm{b}}$ Chlorpyrifos & $\mathrm{CHL}$ & 4.78 & 6.1 & 349.9 & 36 & $97.0(32)$ & $198.0(20)$ & 0.64 \\
\hline
\end{tabular}

aFungicides, binsecticides. 
Table 2. Assessment of the extraction efficiency (EEs,\%) of FPSE using sol-gel CW20M coated fabrics, EFs and average log $K$ values, $n=3$ replicates.,

\begin{tabular}{|c|c|c|c|c|}
\hline \multirow[t]{3}{*}{ Compound } & \multicolumn{2}{|c|}{ Extraction efficiency (\%) \pm SD } & \multirow{3}{*}{$\begin{array}{l}\text { Average } \\
\text { EFs }^{*}\end{array}$} & \multirow{3}{*}{$\begin{array}{c}\text { Average log } \\
\mathrm{K}\end{array}$} \\
\hline & & & & \\
\hline & 3 discs & 6 discs & & \\
\hline PYR & $24 \pm 1$ & $46 \pm 1$ & 8 & $3.35 \pm 0.09$ \\
\hline CYP & $27 \pm 1$ & $50 \pm 3$ & 9 & $3.42 \pm 0.09$ \\
\hline AME & $54 \pm 2$ & $69 \pm 6$ & 18 & $3.85 \pm 0.02$ \\
\hline MET & $35 \pm 2$ & $73 \pm 4$ & 12 & $3.72 \pm 0.28$ \\
\hline PEN & $51 \pm 1$ & $66 \pm 4$ & 17 & $3.79 \pm 0.02$ \\
\hline MYC & $43 \pm 1$ & $52 \pm 2$ & 14 & $3.59 \pm 0.10$ \\
\hline TRI & $10 \pm 1$ & $25 \pm 1$ & 3 & $2.92 \pm 0.12$ \\
\hline FEN & $36 \pm 2$ & $49 \pm 3$ & 12 & $3.50 \pm 0.05$ \\
\hline TEB & $36 \pm 2$ & $52 \pm 2$ & 12 & $3.53 \pm 0.01$ \\
\hline FLU & $59 \pm 3$ & $75 \pm 6$ & 20 & $3.96 \pm 0.01$ \\
\hline IPR & $48 \pm 1$ & $64 \pm 2$ & 16 & $3.75 \pm 0.01$ \\
\hline BEN & $57 \pm 1$ & $76 \pm 3$ & 19 & $3.95 \pm 0.05$ \\
\hline PRO & $48 \pm 1$ & $66 \pm 3$ & 16 & $3.76 \pm 0.02$ \\
\hline BOS & $43 \pm 4$ & $53 \pm 3$ & 14 & $3.60 \pm 0.09$ \\
\hline DIM & $44 \pm 1$ & $58 \pm 2$ & 15 & $3.66 \pm 0.04$ \\
\hline PYRA & $68 \pm 2$ & $83 \pm 4$ & 23 & $4.15 \pm 0.04$ \\
\hline AZO & $42 \pm 1$ & $62 \pm 4$ & 14 & $3.67 \pm 0.04$ \\
\hline DIF & $64 \pm 2$ & $78 \pm 4$ & 21 & $4.04 \pm 0.01$ \\
\hline TRIF & $78 \pm 1$ & $90 \pm 8$ & 26 & $4.39 \pm 0.07$ \\
\hline METH & $31 \pm 3$ & $48 \pm 3$ & 10 & $3.45 \pm 0.01$ \\
\hline CHLM & $65 \pm 15$ & $80 \pm 15$ & 22 & $4.07 \pm 0.02$ \\
\hline $\mathrm{CHL}$ & $78 \pm 11$ & $85 \pm 12$ & 26 & $4.29 \pm 0.07$ \\
\hline
\end{tabular}

${ }^{*}$ Values corresponding to the use of 3 discs 
Table 3. Linearity (0.2-200 $\mathrm{ng} \mathrm{mL} \mathrm{m}^{-1}, \mathrm{n}=9$ addition levels processed in duplicate), LOQs, estimated for red wine, and MRLs of compounds in vinification grapes. Data obtained under equilibrium (overnight extraction) conditons.

\begin{tabular}{|c|c|c|c|c|c|c|c|}
\hline \multirow{3}{*}{$\begin{array}{l}\text { Compo } \\
\text { und } \\
\text { PYR }\end{array}$} & \multicolumn{2}{|c|}{ White wine } & Red wine & \multirow{2}{*}{\multicolumn{2}{|c|}{$\begin{array}{c}\text { Slope ratio } \\
\text { (White wine/ } \\
\text { Red wine) }\end{array}$}} & \multirow{3}{*}{  } & \multirow{3}{*}{$\begin{array}{c}\text { MRLs } \\
\left(\mu g^{-1}\right) \\
5\end{array}$} \\
\hline & \multirow{2}{*}{$\begin{array}{l}\text { Slope } \\
599 \pm 7\end{array}$} & \multirow{2}{*}{$\begin{array}{r}R^{2} \\
0.999\end{array}$} & \multirow{2}{*}{$\begin{array}{l}\text { Slope } \\
596 \pm 6\end{array}$} & & & & \\
\hline & & & & 0.999 & $101 \%$ & & \\
\hline CYP & $2625 \pm 15$ & 0.999 & $2000 \pm 16$ & 0.999 & $135 \%$ & 0.07 & 3 \\
\hline AME & $2432 \pm 44$ & 0.998 & $2954 \pm 21$ & 0.999 & $82 \%$ & 0.07 & 6 \\
\hline MET & $872 \pm 18$ & 0.997 & $900 \pm 12$ & 0.999 & $97 \%$ & 0.3 & 1 \\
\hline PEN & $4328 \pm 63$ & 0.999 & $4019 \pm 93$ & 0.995 & $108 \%$ & 0.03 & 0.4 \\
\hline MYC & $835 \pm 29$ & 0.996 & $1054 \pm 28$ & 0.996 & $79 \%$ & 0.07 & 1 \\
\hline TRI & $422 \pm 7$ & 0.998 & $446 \pm 3$ & 0.999 & $94 \%$ & 0.2 & 0.3 \\
\hline FEN & $634 \pm 14$ & 0.997 & $821 \pm 26$ & 0.994 & $77 \%$ & 0.2 & 15 \\
\hline TEB & $4300 \pm 127$ & 0.995 & $4567 \pm 152$ & 0.993 & $94 \%$ & 0.07 & 1 \\
\hline FLU & $4602 \pm 53$ & 0.999 & $3886 \pm 123$ & 0.994 & $118 \%$ & 0.03 & 0.01 \\
\hline IPR & $2578 \pm 21$ & 0.999 & $2428 \pm 29$ & 0.999 & $106 \%$ & 0.07 & 2 \\
\hline BEN & $7562 \pm 197$ & 0.996 & $6415 \pm 160$ & 0.997 & $118 \%$ & 0.03 & 0.3 \\
\hline PRO & $2449 \pm 18$ & 0.999 & $2279 \pm 20$ & 0.999 & $107 \%$ & 0.07 & 0.3 \\
\hline BOS & $403 \pm 3$ & 0.999 & $501 \pm 12$ & 0.997 & $81 \%$ & 0.03 & 5 \\
\hline${ }^{\mathrm{a} D I M}$ & $927 \pm 16$ & 0.999 & $1330 \pm 39$ & 0.998 & $70 \%$ & 0.2 & 3 \\
\hline PYRA & $5191 \pm 192$ & 0.992 & $4091 \pm 123$ & 0.995 & $127 \%$ & 0.07 & 2 \\
\hline AZO & $3431 \pm 61$ & 0.998 & $4056 \pm 64$ & 0.998 & $85 \%$ & 0.07 & 3 \\
\hline DIF & $4820 \pm 126$ & 0.996 & $4278 \pm 83$ & 0.997 & $113 \%$ & 0.07 & 3 \\
\hline TRIF & $7295 \pm 302$ & 0.990 & $5716 \pm 194$ & 0.995 & $128 \%$ & 0.03 & 3 \\
\hline METH & $660 \pm 5$ & 1.000 & $616 \pm 5$ & 0.999 & $107 \%$ & 0.2 & 0.3 \\
\hline CHLM & $103 \pm 6$ & 0.980 & $100 \pm 4$ & 0.990 & $103 \%$ & 0.3 & 0.2 \\
\hline $\mathrm{CHL}$ & $196 \pm 6$ & 0.995 & $181 \pm 7$ & 0.990 & $108 \%$ & 0.2 & 0.5 \\
\hline
\end{tabular}

${ }^{a} D I M$ was quantified as sum of responses for $E / Z$ isomers 
Table 4. Relative recoveries in wine samples spiked at two different concentration levels: 50 and $10 \mathrm{ng} \mathrm{mL}^{-1}$. White wines (Albariño and Chardonnay) and red wines (Tempranillo and Mencía), $\mathrm{n}=3$ replicates. Relative recoveries obtained against spiked aliquots $\left(0.5\right.$ to $\left.200 \mathrm{ng} \mathrm{mL}^{-1}\right)$ of Verdejo (white wine) and Cabernet Sauvignon (red).

\begin{tabular}{|c|c|c|c|c|c|c|c|c|}
\hline \multirow[b]{3}{*}{ Compound } & \multicolumn{4}{|c|}{ Addition level: $50 \mathrm{ng} \mathrm{mL}^{-1}$} & \multicolumn{4}{|c|}{ Addition level: $10 \mathrm{ng} \mathrm{mL}^{-1}$} \\
\hline & \multicolumn{2}{|c|}{ White wine (Albariño) } & \multicolumn{2}{|c|}{ Red wine (Tempranillo) } & \multicolumn{2}{|c|}{ White wine (Chardonnay) } & \multicolumn{2}{|c|}{ Red wine (Mencía) } \\
\hline & Recovery (\%) & SD & $\begin{array}{l}\text { Recovery } \\
(\%)\end{array}$ & SD & $\begin{array}{l}\text { Recovery } \\
(\%)\end{array}$ & SD & $\begin{array}{l}\text { Recovery } \\
(\%)\end{array}$ & SD \\
\hline PYR & 101 & 9 & 104 & 7 & 93 & 4 & 77 & 6 \\
\hline CYP & 112 & 5 & 101 & 3 & 87 & 4 & 86 & 11 \\
\hline AME & 98 & 4 & 88 & 4 & 90 & 8 & 96 & 14 \\
\hline MET & 101 & 4 & 94 & 3 & 113 & 16 & 94 & 17 \\
\hline PEN & 112 & 2 & 96 & 1 & 102 & 1 & 98 & 8 \\
\hline MYC & 91 & 2 & 82 & 3 & 107 & 9 & 102 & 9 \\
\hline TRI & 118 & 2 & 90 & 3 & 108 & 10 & 102 & 13 \\
\hline FEN & 76 & 3 & 86 & 7 & 95 & 6 & 80 & 12 \\
\hline TEB & 121 & 1 & 91 & 3 & 98 & 6 & 93 & 9 \\
\hline FLU & 111 & 2 & 99 & 1 & 103 & 3 & 100 & 8 \\
\hline IPR & 103 & 3 & 98 & 5 & 106 & 5 & 98 & 12 \\
\hline BEN & 101 & 1 & 103 & 3 & 102 & 1 & 103 & 7 \\
\hline PRO & 111 & 2 & 97 & 2 & 100 & 2 & 102 & 9 \\
\hline BOS & 94 & 6 & 90 & 7 & 97 & 11 & 77 & 14 \\
\hline DIM & 96 & 5 & 88 & 6 & 95 & 20 & 111 & 11 \\
\hline PYRA & 97 & 4 & 107 & 3 & 102 & 3 & 102 & 6 \\
\hline AZO & 100 & 4 & 94 & 6 & 105 & 11 & 101 & 14 \\
\hline DIF & 109 & 3 & 102 & 3 & 100 & 3 & 103 & 7 \\
\hline TRIF & 95 & 5 & 118 & 5 & 103 & 5 & 102 & 6 \\
\hline METH & 99 & 2 & 105 & 2 & 106 & 11 & 97 & 11 \\
\hline CHLM & 105 & 5 & 94 & 6 & 114 & 6 & 102 & 9 \\
\hline $\mathrm{CHL}$ & 98 & 3 & 105 & 3 & 105 & 5 & 104 & 4 \\
\hline
\end{tabular}


Table 5. Concentrations of fungicides measured in different commercial wine samples, $n=3$ replicates. Empty cells correspond to non-detected compounds.

\begin{tabular}{|c|c|c|c|c|c|c|c|c|c|}
\hline \multirow[b]{2}{*}{ Compound } & \multicolumn{9}{|c|}{ Concentration $\mathrm{ng} \mathrm{mL}^{-1} \pm \mathrm{SD}$} \\
\hline & aSample 1 & aSample 2 & aSample 3 & aSample 4 & aSample 5 & bSample 6 & bSample 7 & bSample 8 & bSample 9 \\
\hline PYR & & $1.2 \pm 0.1$ & & & & & & & $2.6 \pm 0.2$ \\
\hline CYP & & & & & & & & & $0.3 \pm 0.1$ \\
\hline AME & & $4.6 \pm 0.4$ & & $12.6 \pm 0.9$ & & & & & \\
\hline MET & $1.0 \pm 0.1$ & & $1.3 \pm 0.2$ & $7.5 \pm 0.6$ & $0.7 \pm 0.1$ & $5.1 \pm 0.4$ & $2.4 \pm 0.2$ & & \\
\hline PEN & & & & & & & & & $0.2 \pm 0.1$ \\
\hline \multirow[t]{2}{*}{ MYC } & $0.9 \pm 0.1$ & $0.49 \pm 0.07$ & & & $0.6 \pm 0.2$ & & & $1.0 \pm$ & $0.6 \pm 0.1$ \\
\hline & & & & & & & & 0.2 & \\
\hline TRI & & & & & $1.6 \pm 0.1$ & $1.1 \pm 0.1$ & & & \\
\hline FEN & & $16 \pm 2$ & $15.3 \pm 1.3$ & & & & & & $1.0 \pm 0.2$ \\
\hline \multirow[t]{2}{*}{ TEB } & $7.4 \pm 0.5$ & & & & $1.7 \pm 0.2$ & $2.2 \pm 0.2$ & $1.3 \pm 0.2$ & $7.1 \pm$ & $28.1 \pm 1.2$ \\
\hline & & & & & & & & 0.5 & \\
\hline IPR & & & $130 \pm 9$ & $5.3 \pm 0.4$ & & & & & \\
\hline BEN & $0.4 \pm 0.1$ & & & & & & & & \\
\hline BOS & $9.0 \pm 1.6$ & $18.2 \pm 1.6$ & & $3.2 \pm 0.4$ & $3.8 \pm 0.4$ & $1.4 \pm 0.1$ & $2.2 \pm 0.3$ & & $1.1 \pm 0.3$ \\
\hline DIM & & $3.0 \pm 0.3$ & & $4.0 \pm 0.6$ & & & & & \\
\hline AZO & & & & & & & & & $0.5 \pm 0.1$ \\
\hline DIF & & & & & $0.2 \pm 0.1$ & & & & $0.2 \pm 0.1$ \\
\hline
\end{tabular}

\footnotetext{
${ }^{a}$ White wine, ${ }^{b}$ Red wine
} 
Supplementary material

Fabric Phase Sorptive Extraction Followed by Ultra Performance Liquid Chromatography

Tandem Mass Spectrometry for the Determination of Fungicides and Insecticides in Wine

Pérez-Mayánª, L.; Rodriguez, la .; Ramil, M. ${ }^{\text {a }}$ Kabir, A ; Furton, K. G. ${ }^{\text {b. Cela, R. }}{ }^{a}$

${ }^{a}$ Department of Analytical Chemistry, Nutrition and Food Sciences, IIAA-Institute for Food Analysis and Research, Universidade de Santiago de Compostela, R/Constantino Candeira SN, 15782 Santiago de Compostela, Spain

${ }^{b}$ International Forensic Research Institute, Department of Chemistry and Biochemistry, Florida International University, 11200 SW $8^{\text {th }}$ Street, Miami, FL 33199, USA 
Fig. S1. FT-IR spectra of (a) uncoated cellulose fabric; (b) CW20M polymer; and (c) sol-gel CW20M coated FPSE medium
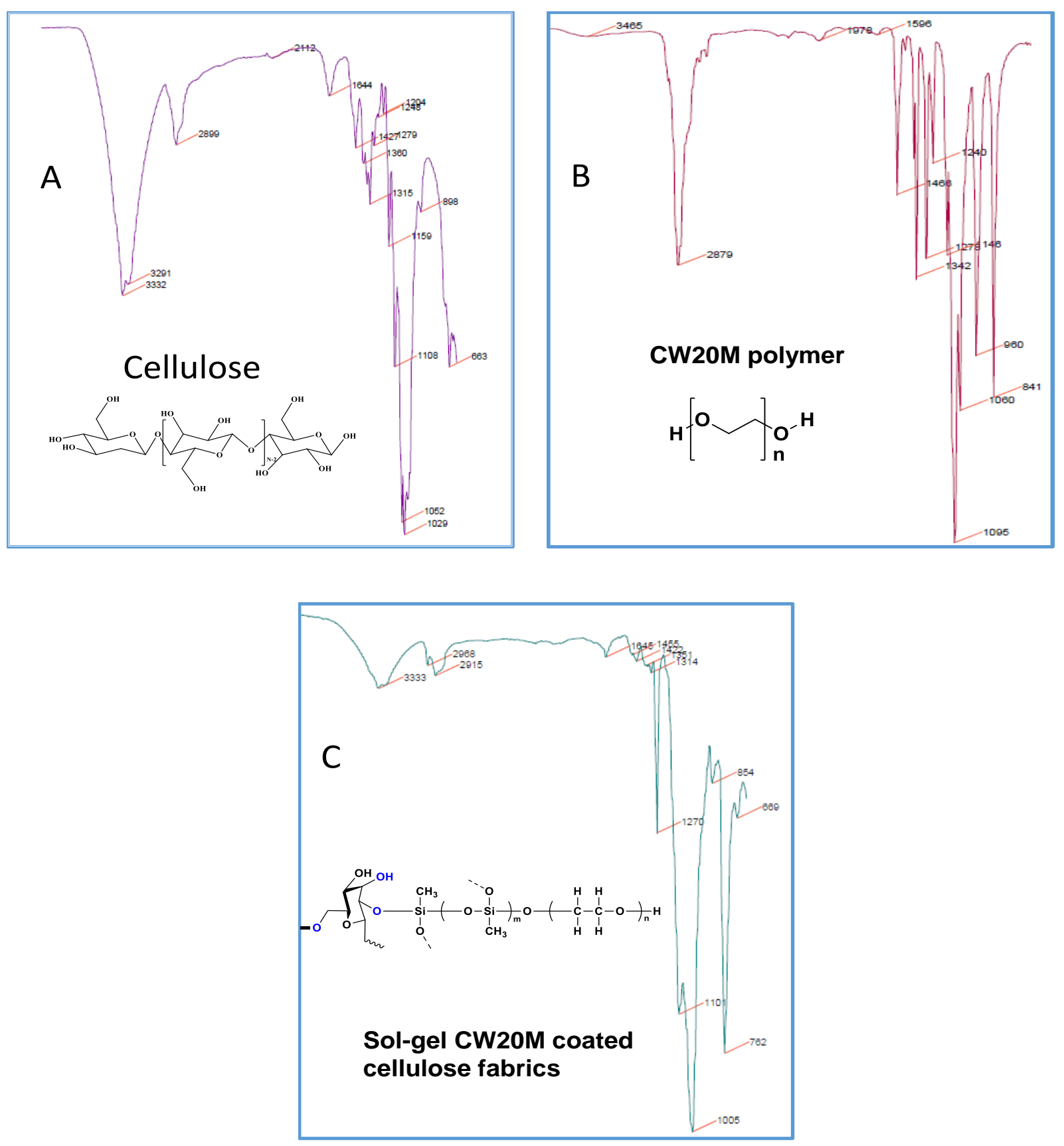
Fig. S2. Relative extraction efficiencies obtained with the cotton substrate, without coating, versus CW2OM coated fabrics, $\mathrm{n}=3$ replicates. Data corresponding to three $4 \mathrm{~mm}$ diameter discs, with overnight sampling.

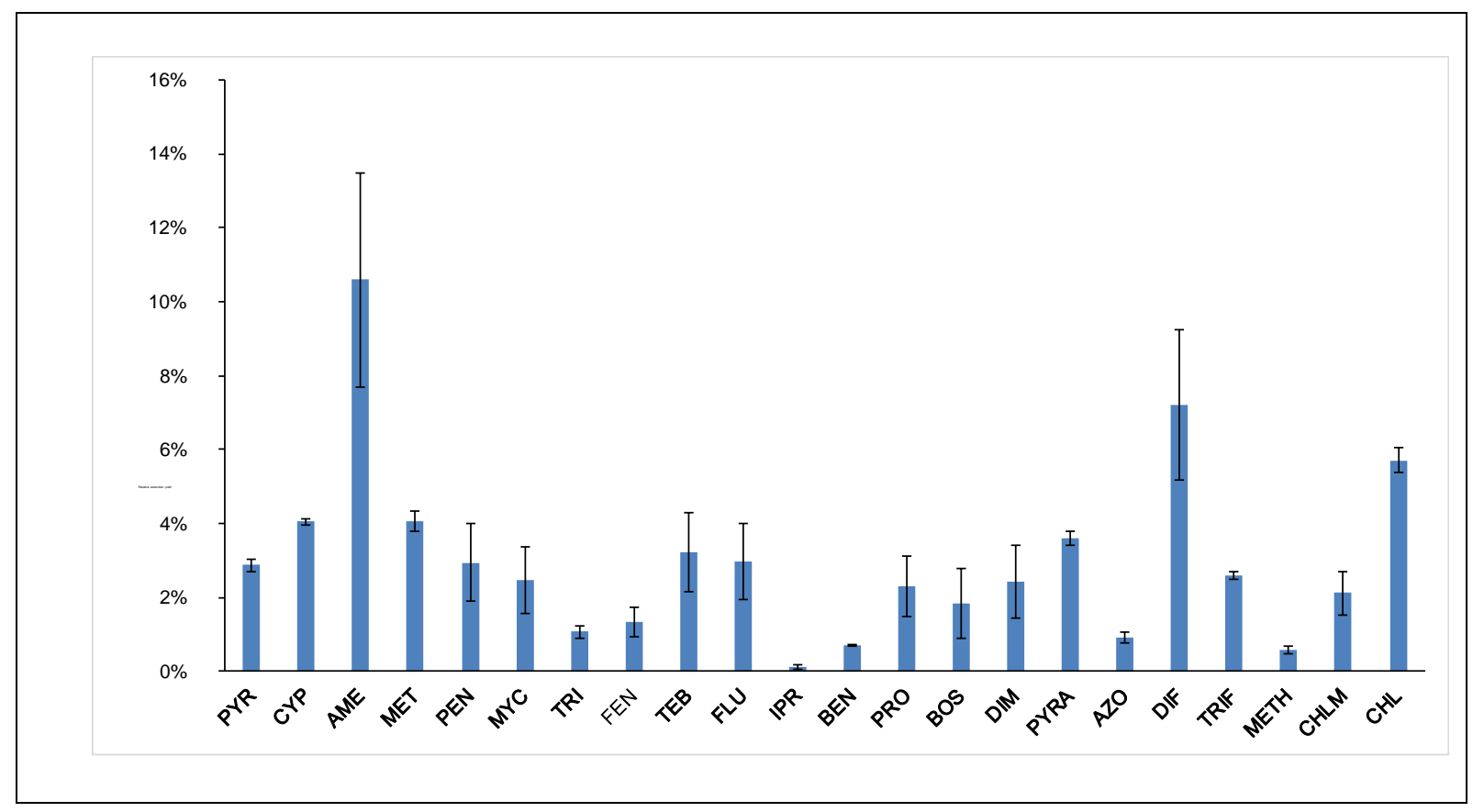

Fig. S3. Comparison of responses for FPSE process for selected compounds. Each point represents the average response for triplicate extractions. Responses are normalized to those obtained without addition of $\mathrm{NaCl}$

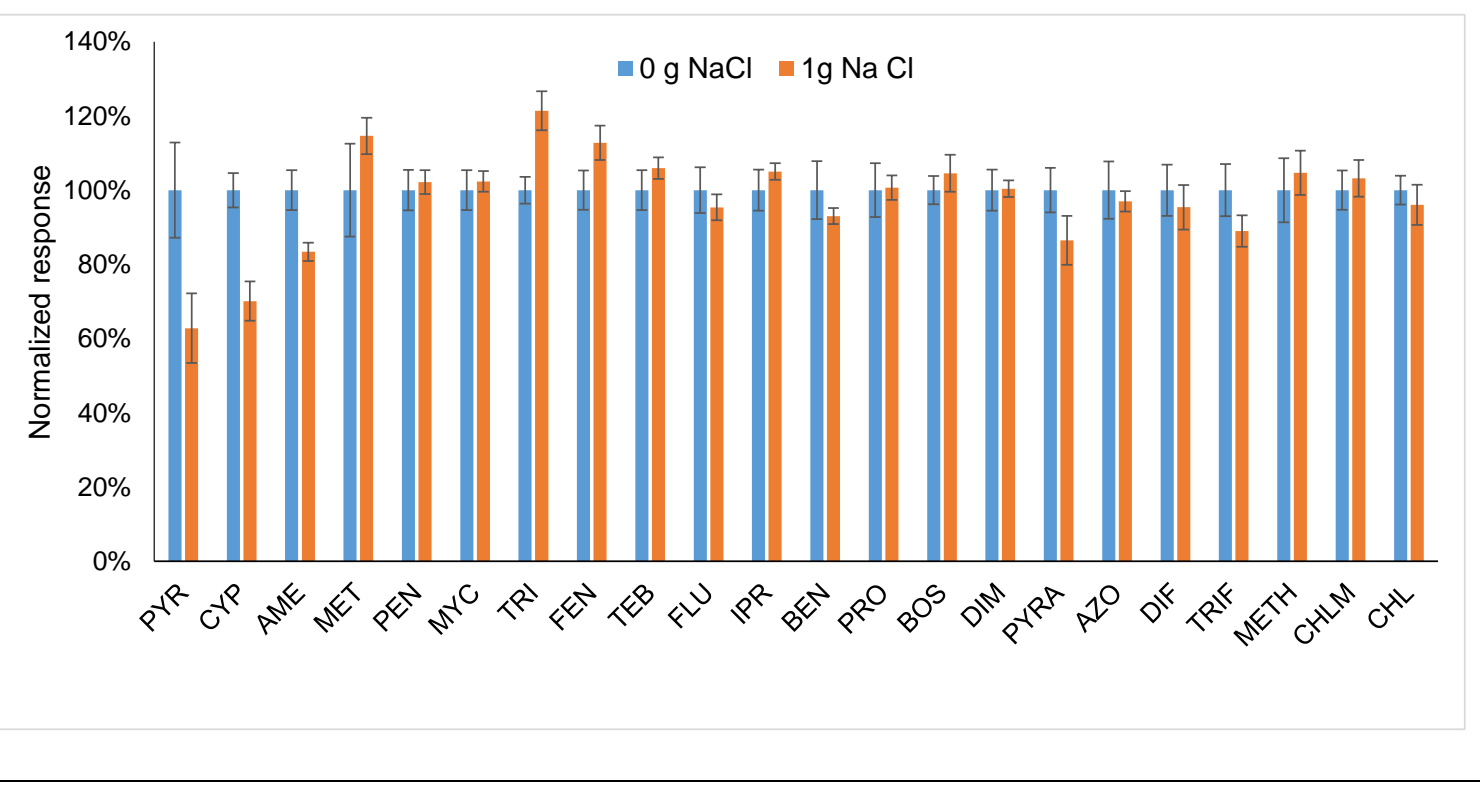


Fig. S4. Extraction kinetics using six FPSE discs coated with the CW20M polymer.

Fig. S5. Plots of EEs (\%) versus Log D values. A, data obtained for 3 discs. B, data for 6 discs.




Figure S6. Effect of the number of extraction-desorption cycles in the efficiency of the FPSE process. Normalized responses to those obtained in the first cycle. Average data with standard deviations for 5 replicates.
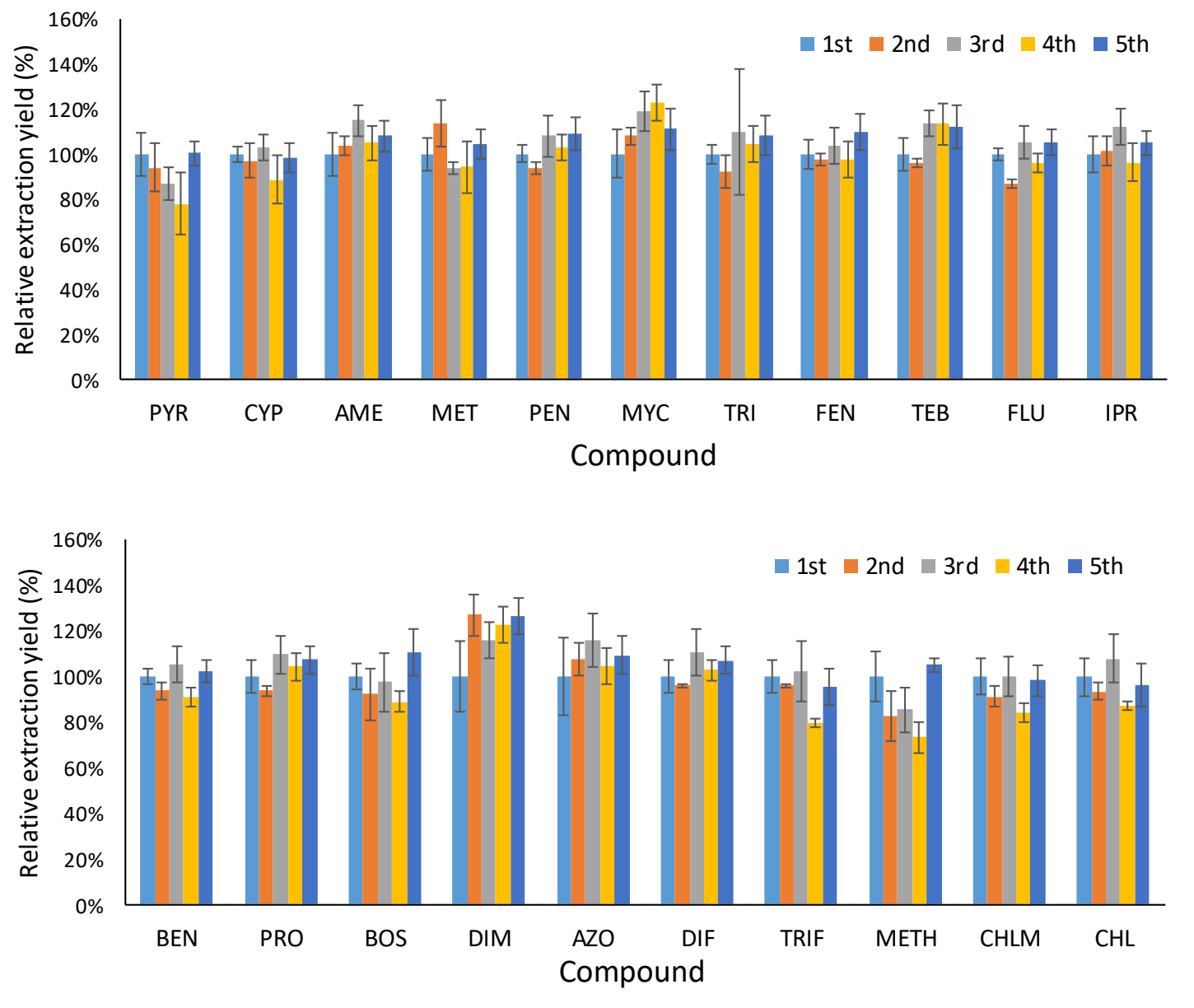
Table S1. Sol solution composition and other relevant information

\begin{tabular}{|c|c|c|c|c|c|c|}
\hline Sorbent & \begin{tabular}{|l|} 
Inorga \\
nic \\
Precursor \\
\end{tabular} & Organic Polymer & Catalyst & Solvent System & $\begin{array}{c}\text { Sorbent } \\
\text { Loading } \\
\left(\mathbf{m g ~ c m}^{-2}\right) \\
\end{array}$ & Schematic of Sol-gel Sorbent Coated FPSE Media \\
\hline $\begin{array}{l}\text { Sol-gel } \\
\text { CW20M }\end{array}$ & \begin{tabular}{|c|}
$\mathrm{CH}_{3}$ \\
$\mathrm{H}_{3} \mathrm{CO}-\mathrm{si}_{-}-\mathrm{OCH}_{3}$ \\
$\mathrm{OCH}_{3}$
\end{tabular} & ${ }_{H} l^{O}$ & $\begin{array}{r}\text { TFA } \\
\left(5 \% \mathrm{H}_{2} \mathrm{O}\right)\end{array}$ & $\begin{array}{l}\text { Dichloromethane: } \\
\text { Acetone } \\
(50: 50 \text { v v })\end{array}$ & 8.63 & \\
\hline $\begin{array}{l}\text { Sol-gel } \\
\text { PEG- } \\
\text { PPG-PEG }\end{array}$ & \begin{tabular}{|c|}
$\mathrm{CH}_{3}$ \\
$\mathrm{H}_{3} \mathrm{CO}-\mathrm{Si}_{-}-\mathrm{OCH}_{3}$ \\
$\mathrm{OCCH}_{3}$
\end{tabular} &  & $\begin{array}{r}\text { TFA } \\
\left(5 \% \mathrm{H}_{2} \mathrm{O}\right)\end{array}$ & $\begin{array}{l}\text { Dichloromethane: } \\
\text { Acetone } \\
(50: 50 \mathrm{v} / \mathrm{v})\end{array}$ & 5.68 & \\
\hline $\begin{array}{l}\text { Sol-gel PCAP- } \\
\text { PDMS-PCAP }\end{array}$ & \begin{tabular}{c|}
$\mathrm{CH}_{3}$ \\
$\mathrm{H}_{3} \mathrm{CO}-\mathrm{Si}_{\mathrm{i}}-\mathrm{OCH}_{3}$ \\
$\mathrm{OCCH}_{3}$
\end{tabular} & & $\begin{array}{r}\text { TFA } \\
f_{n}^{-H}\left(5 \% \mathbf{H}_{2} \mathrm{O}\right)\end{array}$ & $\begin{array}{l}\text { Dichloromethane: } \\
\text { Acetone } \\
(50: 50 \mathrm{v} / \mathrm{v})\end{array}$ & 6.14 & \\
\hline \begin{tabular}{l}
\multicolumn{1}{c}{ Sol-gel } \\
Polycaprolactone \\
Triol
\end{tabular} & \begin{tabular}{|c|}
$\mathrm{CH}_{3}$ \\
$\mathrm{H}_{3} \mathrm{CO}-\mathrm{Si}_{-}-\mathrm{OCH}_{3}$ \\
$\mathrm{OCH}_{3}$ \\
$\mathrm{O}_{3}$
\end{tabular} & & $\begin{array}{r}\text { TFA } \\
n^{H} \\
\left(5 \% \mathbf{H}_{2} \mathbf{O}\right)\end{array}$ & $\begin{array}{c}\text { Dichloromethane: } \\
\text { Acetone } \\
(\mathbf{5 0 : 5 0} \mathrm{v} / \mathrm{v})\end{array}$ & 3.46 & \\
\hline Sol-gel PTHF & $\begin{array}{c}\mathrm{CH}_{3} \\
\mathrm{I}_{3} \mathrm{CO}-\mathrm{Si}-\mathrm{OCH}_{3} \\
\mathrm{OCH}_{3}\end{array}$ & но_/ & $\begin{array}{r}\text { TFA } \\
\left(5 \% \mathrm{H}_{2} \mathbf{O}\right)\end{array}$ & $\begin{array}{c}\text { Dichloromethane: } \\
\text { Acetone } \\
(\mathbf{5 0 : 5 0} \mathrm{v} / \mathrm{v})\end{array}$ & 3.96 & \\
\hline
\end{tabular}


Table S2. Compound names, molar masses, chemical structures and topological polar surface areas (TPSA)

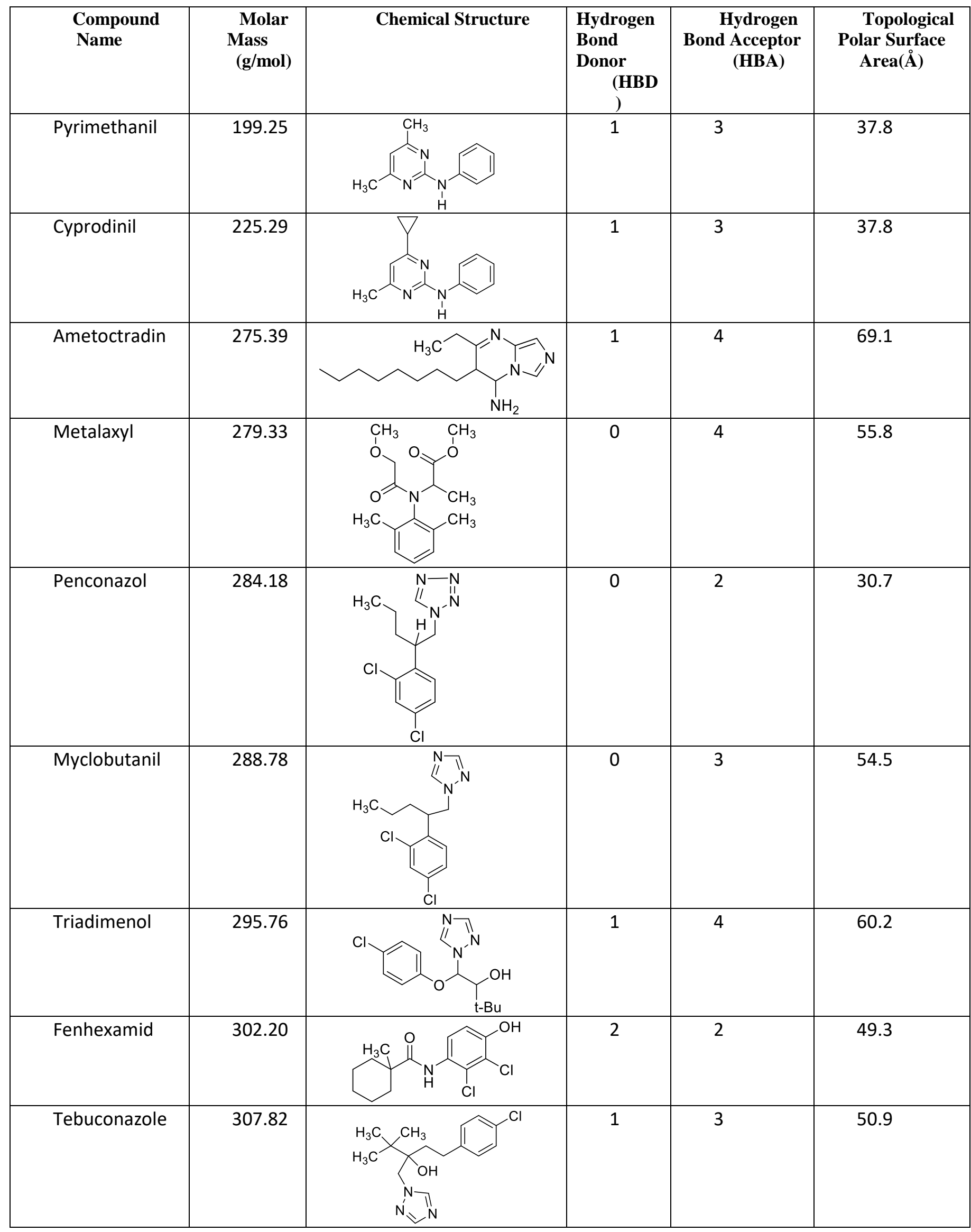












Table S3. Linearity $(0.5-200 \mathrm{ng} \mathrm{mL}-1, \mathrm{n}=8$ addition levels processed in duplicate), ratio of slopes (white/red wine) and estimated LOQs considering a $3 \mathrm{~h}$ sampling step.

\begin{tabular}{|c|c|c|c|c|}
\hline \multirow[b]{2}{*}{$\begin{array}{l}\text { Compo } \\
\text { und }\end{array}$} & \multicolumn{2}{|c|}{$R^{2}$ values } & \multirow{2}{*}{$\begin{array}{c}\text { Slope ratio } \\
\text { (White } \\
\text { wine/ } \\
\text { Red wine) }\end{array}$} & \multirow{2}{*}{$\begin{array}{l}\text { LOQs } \\
\begin{array}{c}(\mathrm{ng} \\
\left.\mathrm{mL}^{-1}\right)\end{array}\end{array}$} \\
\hline & White wine & Red wine & & \\
\hline PYR & 0.996 & 0.992 & $108 \%$ & 0.7 \\
\hline CYP & 0.997 & 0.994 & $93 \%$ & 0.2 \\
\hline AME & 0.998 & 0.991 & $83 \%$ & 0.2 \\
\hline MET & 0.998 & 0.992 & $104 \%$ & 0.8 \\
\hline PEN & 0.999 & 0.993 & $103 \%$ & 0.1 \\
\hline MYC & 0.999 & 0.992 & $110 \%$ & 0.2 \\
\hline TRI & 0.998 & 0.990 & $114 \%$ & 0.5 \\
\hline FEN & 0.996 & 0.991 & $123 \%$ & 0.5 \\
\hline TEB & 0.998 & 0.988 & $102 \%$ & 0.2 \\
\hline FLU & 0.999 & 0.990 & $123 \%$ & 0.1 \\
\hline IPR & 0.999 & 0.990 & $130 \%$ & 0.2 \\
\hline BEN & 0.999 & 0.989 & $126 \%$ & 0.1 \\
\hline PRO & 0.999 & 0.990 & $131 \%$ & 0.2 \\
\hline BOS & 0.994 & 0.993 & $107 \%$ & 0.2 \\
\hline${ }^{\mathrm{a} D I M}$ & 0.996 & 0.991 & $130 \%$ & 0.5 \\
\hline PYRA & 0.999 & 0.991 & $111 \%$ & 0.2 \\
\hline $\mathrm{AZO}$ & 0.997 & 0.991 & $120 \%$ & 0.2 \\
\hline DIF & 0.998 & 0.986 & $139 \%$ & 0.2 \\
\hline TRIF & 0.996 & 0.984 & $114 \%$ & 0.1 \\
\hline METH & 0.998 & 0.999 & $92 \%$ & 0.5 \\
\hline CHLM & 0.999 & 0.990 & $116 \%$ & 1 \\
\hline $\mathrm{CHL}$ & 0.999 & 0.990 & $121 \%$ & 0.7 \\
\hline
\end{tabular}

${ }^{\mathrm{a} D I M}$ was quantified as sum of responses for $\mathrm{E} / \mathrm{Z}$ isomers 